\title{
A New Phenotypic Classification System for Dyslipidemias Based on the Standard Lipid Panel
}

\author{
Maureen Sampson \\ National Institutes of Health https://orcid.org/0000-0003-0885-250X \\ Rami Ballout \\ NHLBI: National Heart Lung and Blood Institute \\ Daniel Soffer \\ Penn Medicine \\ Anna Wolska \\ NHLBI: National Heart Lung and Blood Institute \\ Sierra Wilson \\ NHLBI: National Heart Lung and Blood Institute \\ Jeffrey Meeusen \\ Mayo Clinic Minnesota \\ Leslie Donato \\ Mayo Clinic Minnesota \\ Erica Fatica \\ Mayo Clinic Minnesota \\ James Otvos \\ LabCorp: Laboratory Corporation of America \\ Eliot Brinton \\ Utah Lipid Center \\ Robert Rosenson \\ Icahn School of Medicine at Mount Sinai \\ Peter Wilson \\ Emory Clinical Cardiovascular Research Institute \\ Marcelo Amar \\ NHLBI: National Heart Lung and Blood Institute \\ Robert Shamburek \\ NHLBI: National Heart Lung and Blood Institute \\ Sotirios Karathanasis \\ NHLBI: National Heart Lung and Blood Institute \\ Alan Remaley ( $\nabla$ alan.remaley@nih.gov) \\ NHLBI: National Heart Lung and Blood Institute
}

\section{Research Article}

Keywords: cholesterol, LDL, lipids, lipoproteins, genetics, cardiovascular disease

Posted Date: September 29th, 2021

DOI: https://doi.org/10.21203/rs.3.rs-923991/v1

License: (c) (i) This work is licensed under a Creative Commons Attribution 4.0 International License. Read Full License

Version of Record: A version of this preprint was published at Lipids in Health and Disease on November 27th, 2021. See the published version at https://doi.org/10.1186/s12944-021-01585-8. 


\section{Abstract \\ BACKGROUND}

Dyslipoproteinemias can be classified by their distinct lipoprotein patterns, which helps determine atherosclerotic cardiovascular disease (ASCVD) risk and directs lipid management but this has required advanced laboratory testing.

\section{OBJECTIVE}

To develop a new algorithm for classifying lipoprotein disorders that only relies on the standard lipid panel.

\section{METHODS}

Lipid thresholds for defining the different lipoprotein phenotypes were derived for Non-High-Density Lipoprotein-Cholesterol (NonHDL-C) and Triglycerides (TG) to be concordant when possible with the current US Multi-Society guidelines for blood cholesterol management.

\section{RESULTS}

The new classification method categorizes patients into all the classical Fredrickson-like phenotypes except for Type III dysbetalipoproteinemia. In addition, a new hypolipidemic phenotype (Type $\mathrm{VI}$ ) due to genetic mutations in apoB-metabolism is described. The validity of the new algorithm was confirmed by lipid analysis by NMR $(N=11,365)$ and by concordance with classification by agarose gel electrophoresis/beta-quantification $(N=5504)$. Furthermore, based on the Atherosclerosis Risk in Communities (ARIC) cohort $(\mathrm{N}=14742)$, the lipoprotein phenotypes differ in their association with ASCVD (TypeV > Ilb > IVb > Ila > IVa > normolipidemic) and can be used prognostically as risk enhancer conditions in the management of patients.

\section{CONCLUSIONS}

We describe a clinically useful lipoprotein phenotyping system that is only dependent upon the standard lipid panel. It, therefore, can be easily implemented for increasing compliance with current guidelines and for improving the care of patients at risk for ASCVD.

\section{Highlights}

- A new algorithm is described for categorizing dyslipidemic patients into Fredrickson-like lipoprotein phenotypes except for Type III.

- The new lipoprotein phenotypes were validated by NMR-lipoprotein analysis and by agarose gel electrophoresis/beta-quantification in a large number of subjects.

- The new lipoprotein phenotyping system identifies high-risk cardiovascular patients and helps direct clinical management.

- A major advance is that the new lipoprotein phenotypes are based on just the standard lipid panel, and thus can be automatically calculated by the clinical laboratory and widely implemented.

\section{Background}

Elevated plasma lipids, in particular total cholesterol (TC) and triglycerides (TG), increase the risk of atherosclerotic cardiovascular disease (ASCVD); hence, their measurement is integral to ASCVD risk assessment and prevention [1]. The levels of TC and TG in plasma are influenced by a complex network of metabolic pathways, which when disturbed by disease or environmental influences, will alter the concentration of the various lipoproteins that transport these lipids in the circulation. Perturbations in the normal physiologic level of plasma lipoproteins were first noted over 50 years ago by Donald S. Fredrickson and colleagues, whose observations became the foundation for the first phenotypic classification of lipoprotein disorders [2-6].

The three main classes of apolipoprotein B (apoB)-containing lipoprotein particles are Low-Density Lipoproteins (LDL), Very-Low Density Lipoproteins (VLDL) and chylomicrons. Nearly all possible permutations for elevations in these lipoproteins, taken one or two at a time, comprise the classic Fredrickson classification system. Three of these phenotypes are characterized by an increase in a single type of lipoprotein, namely Type I (chylomicrons), Type lla (LDL), and Type IV (VLDL). In the Types Ilb and V phenotypes, two classes of lipoproteins are increased, and thus they are sometimes called mixed dyslipoproteinemias. In Type Ilb, there is an increase in both VLDL and LDL, whereas in Type V both VLDL and chylomicrons are increased. The only other possible permutation for simultaneous elevations in two lipoprotein classes would be an increase in LDL and chylomicrons, but this pattern has only been described in a single case report [7]. The other remaining Fredrickson phenotype is Type III. It is a relatively uncommon disorder characterized by the accumulation of cholesterol-enriched remnant particles, due to impaired apoE-mediated hepatic clearance of partially lipolyzed VLDL and chylomicrons [8]. It is important to note that the Fredrickson classification system does not address dyslipidemias related to low HDL-C or elevated Lp(a).

The Fredrickson classification was originally established by separating lipoproteins by density gradient ultracentrifugation (beta-quantification), but later it was mostly performed by the more convenient method of agarose gel electrophoresis[9]. Although the classification of Fredrickson lipoprotein phenotypes is still used for didactic purposes, it is currently only available in specialty reference laboratories and is no longer widely used in clinical practice[9]. The gradual 
discontinuation of detailed lipoprotein phenotyping, starting in the late 1980s, was largely driven by the advent of statin therapy. Contemporary guidelines have almost exclusively focused on reducing LDL-C with statins as the initial approach for ASCVD risk reduction by lipid-lowering therapy.

In 2007, Allan D. Sniderman and colleagues described a modification of the Fredrickson classification system in which apoB, along with TC and TG, were used as surrogate measures of lipoprotein concentrations [10]. They also made several well-reasoned recommendations on how lipoprotein phenotyping could enhance the clinical management of patients in the modern era, including the use of various lipid therapies that alter other lipid parameters besides LDL-C[11]. Since that time, additional lipid-lowering drugs have been approved, particularly for hypertriglyceridemia, which may benefit from a more refined classification of lipoprotein phenotypes [12, 13].

The current 2018-Multiscociety Blood Cholesterol Guideline[1] and the National Lipid Association (NLA) Recommendations[14] on lipid management for the primary prevention of ASCVD, still mostly depend on the standard lipid panel (TC, TG, and HDL-C), which can be used to estimate LDL-C [15]. Although ApoB can be accurately measured and can improve ASCVD risk assessment [16, 17], it is not recommended as a primary screening test by current US guidelines. This decision was made, in part, in order to simplify the screening process and because the addition of apoB to the standard lipid panel testing would approximately double the cost for ASCVD-risk screening [18].

In an effort both to be cost-effective and to conform with existing US guidelines, we have developed a new algorithm for lipoprotein phenotyping based on just two components of the standard lipid panel, namely TG and NonHDL-C (TC minus HDL-C). The new classification system depends upon 7 lipid cut-points already recommended by the 2018-Multiscociety Guideline for patient management [1], plus two non-traditional lipid-based rules. Although this new classification system cannot be used for identifying Type III dyslipidemia, it does identify the other more common Fredrickson phenotypes related to apoBcontaining lipoproteins. A new phenotype, Type $\mathrm{VI}$, which occurs due to rare genetic disorders in apoB-metabolism and requires a specific treatment, is also described. Finally, we show how this new lipoprotein phenotyping system can serve as a general guide or framework, particularly for the non-lipid specialist, in the diagnosis and clinical management of patients at risk for ASCVD.

\section{Materials And Methods Study design and biochemical measurements}

Laboratory, observational study lipid databases, and ASCVD outcome experience from large observational cohorts were used to develop, cross-validate, and examine the potential utility of the new lipoprotein phenotyping method. Research under this study was considered non-human subject research and was exempted by the NIH-IRB.

Standard lipid panel tests $(\mathrm{N}=32,696)$, measured by standard enzymatic methods, plus apoB, were performed on the Cobas 6000 analyzer (Roche) on patients $(N=14,120)$ tested on multiple occasions at the NIH Clinical Center from 2013-2018. Patients in the study included those with a normal lipoprotein profile and also a wide variety of rare lipid disorders. Patients on lipid-lowering therapy were not excluded from analysis. NMR LipoProfile analysis (LabCorp) was also performed on a convenience-derived subset of the same samples $(\mathrm{N}=11,365)$, using the Vantera NMR analyzer and LP4 deconvolution algorithms[19]. De-identified clinical laboratory test results from the National Health and Nutrition Examination Survey $(\mathrm{NHANES}, 2005-2016)(\mathrm{N}=13,086)$ were used for external validation and downloaded from the following website: https://wwwn.cdc.gov/nchs/nhanes/. De-identified datasets for external validation were also obtained from the Multi Ethnic Study of Atherosclerosis (MESA) $(\mathrm{N}=6788)$ and the Atherosclerosis Risk in Communities (ARIC) ( $\mathrm{N}=$ 14742), using BioLINCC (https://biolincc.nhlbi.nih.gov/home/). Metabolic Syndrome was defined using 2004-AHA guidelines [20].

Routine diagnostic testing for lipoprotein phenotyping of patients $(\mathrm{N}=5602)$ was performed at Mayo Clinic Laboratories, using a combination of agarose gel electrophoresis and beta-quantification (gel-lipid method). The lipid phenotype was assigned after reviewing agarose gel electrophoresis in the context of LDL$\mathrm{C}$ as determined by beta-quantification ( $\mathrm{LDL}-\mathrm{C}_{\beta Q}$ ) and other lipid values as described below. Serum was ultracentrifuged for 15 hours at $75,000 \mathrm{x} \mathrm{g}$ to generate a supernatant with density $<1.006 \mathrm{~g} / \mathrm{L}$. The upper layer (containing chylomicrons and VLDL) and lower layer (containing HDL and LDL) were separated and transferred to aliquot tubes. TC and TG concentrations were determined enzymatically in whole serum and in both density layers. HDL-C was determined following selective precipitation of LDL from the lower layer, using a mixture of magnesium chloride and dextran sulfate. LDL- $\mathrm{C}_{\beta Q}$ is calculated as ([lower layer cholesterol] - [HDL-C]). Phenotypes were assigned according to the following criteria: (1) Type I = abundant chylomicrons with minimal VLDL detected on gel and VLDL-layer Cholesterol/TG ratio $\left(V_{\text {ratio }}\right)<0.1$. (2) Type lla $=L D L-C_{B Q}>190 \mathrm{mg} / \mathrm{dL}$ and VLDL-layer $T G<120 \mathrm{mg} / \mathrm{dL}$ (mild Ila if LDL- $\mathrm{C}_{B Q}=160-189$ ). (3) Type $\mathrm{Ilb}=\mathrm{LDL}-\mathrm{C}_{\mathrm{BQ}}>190 \mathrm{mg} / \mathrm{dL}$ and VLDL-layer TG $>120 \mathrm{mg} / \mathrm{dL}$ (mild Ilb if LDL-C $\mathrm{C}_{B Q}=160-189 \mathrm{mg} / \mathrm{dL}$ ). (4) Type III = floating beta-VLDL on gel and VLDL-layer TG > $120 \mathrm{mg} / \mathrm{dL}$ and $\mathrm{V}_{\text {ratio }}>0.33$. (5) Type IV = LDL- $\mathrm{C}_{B Q}<160 \mathrm{mg} / \mathrm{dL}$ and VLDL-layer TG > 250mg/dL (mild if VLDL-layer TG = 120-249 mg/dL). (6) Type V = chylomicrons and VLDL detected on gel and total plasma $T G>1000 \mathrm{mg} / \mathrm{dL}$ and $\mathrm{V}_{\text {ratio }}<0.2$.

\section{Statistical Methods}

Mean differences between groups were analyzed by ANOVA, or t-test, in case of two groups, with $\mathrm{P}<0.05$ considered statistically significant. Statistical analysis was performed using JMP software (SAS, NC). Software developed for lipoprotein phenotyping analysis by the newly developed method can be freely downloaded at the following website: https://figshare.com/articles/software/Sampson_Phenotype_Calculator/16617490

\section{Results}

\section{Lipid cut-points for new classification system for lipoprotein phenotypes}


A diagram of our new classification system for lipoprotein phenotypes is shown in Fig. 1 and as a flowchart in Supplemental Fig. 1. The two vertical TG cutpoints of 175 and $500 \mathrm{mg} / \mathrm{dL}$ are based on the 2018-Multiscociety Guideline for lipids[1]. In these guidelines, TG > 175 mg/dL is used to define hypertriglyceridemia, which we also use to identify the 4 traditional hypertriglyceridemic phenotypes (Type I, Illb, IV, and V). When TG > 500 mg/dL, one should consider the use of TG- lowering therapy for reducing the risk of pancreatitis [1] and is the cut-point that the FDA uses for the approval of TG-lowering drugs for the prevention of pancreatitis. We used this same TG cut-point to distinguish Type I and V phenotypes, which are at increased risk of pancreatitis [21] [22], from Type Ilb and Type IV, which have more moderate increases in TG and a lower risk for pancreatitis.

Most of the nonHDL-C cut-points are based on the following guidelines [1] for stratifying ASCVD risk by LDL-C: LDL-C $\geq 190 \mathrm{mg} / \mathrm{dL}$, a criteria often used to define high risk Type lla patients [23], LDL-C between 160-190 mg/dL (Normolipidemic High risk ( $\mathrm{N}_{\mathrm{H}}$ )), LDL-C between 70-160 mg/dL (Normolipidemic Moderate risk $\left(\mathrm{N}_{\mathrm{M}}\right)$, and $\mathrm{LDL}<70 \mathrm{mg} / \mathrm{dL}$ (Normolipidemic Low risk $\left(\mathrm{N}_{\mathrm{L}}\right)$. To convert these LDL-C limits into nonHDL-C units, the Friedewald equation was rearranged to calculate NonHDL-C (NonHDL-C $=$ LDL-C $+0.2 T G)$ and LDL-C was fixed at either 190, 160 or $70 \mathrm{mg} / \mathrm{dL}$, thereby creating the three diagonal nonHDL-C boundary lines seen in Fig. 1.

For TG between 175 and 500 mg/dL, there are two additional horizontal nonHDL-C boundary lines (Fig. 1). The top line defines the boundary between Type Ilb and Type IV and was fixed at a NonHDL-C of $220 \mathrm{mg} / \mathrm{dL}$, the decision point recommended instead of LDL-C to initiate statin treatment in hypertriglyceridemic patients, according to 2015-NLA recommendations[14], which is also consistent with the current 2018-Multiscociety Guideline[1], as well as older US guidelines[24]. The lower NonHDL-C cut-point of $130 \mathrm{mg} / \mathrm{dL}$ is currently used as an alternative for LDL-C in defining patients at lower risk for ASCVD [1]. We used this cut-point for dividing the Type IV phenotype into two subtypes (Type IVa and Type IVb). As will be shown later, compared to Type IVb, subjects with Type IVa have a higher proportion of large Triglyceride-rich lipoprotein (TRL) particles than small TRL particles and are at a lower risk for ASCVD. We also use this cut-point because now that the 2018-Multisociety Guideline [1] has endorsed the use of non-fasting samples for screening, it is likely that many nonfasting patients may have plasma lipids that transiently fall into Type IVb phenotype but may have a more normolipidemic phenotype when fasting.

For TG $\geq 500 \mathrm{mg} / \mathrm{dL}$, we have one horizontal boundary line at a fixed NonHDL-C value of $110 \mathrm{mg} / \mathrm{dL}$ (Fig. 1), a non-traditional lipid cut-point. We chose it, because it approximately corresponds to the apoB decision limit of $75 \mathrm{mg} / \mathrm{dL}$ (Supplemental Fig. 2), which is one of the rules used in the Sniderman classification [10] to distinguish Type I from Type V. We, therefore, define Type V as all patients with a TG $\geq 500 \mathrm{mg} / \mathrm{dL}$ and a NonHDL-C $\geq 110 \mathrm{mg} / \mathrm{dL}$. This phenotype has the widest range of lipid values in our classification system, but it is sparsely populated. Unlike Type I, patients with this condition usually present in adulthood and are characterized as having high interindividual variability in their plasma lipids $[25,26]$, which can fall anywhere in the upper right quadrant of the plot (Fig. 1).

We also describe a new lipoprotein phenotype designated as Type VI. It is based on a compound lipid rule (NonHDL-C $\leq 30 \mathrm{mg} / \mathrm{dL}$ ( $\leq 0.02 \mathrm{st}$ percentile) and a $\mathrm{TG} \leq 30 \mathrm{mg} / \mathrm{dL}$ ( $\leq 1 \mathrm{st}$ percentile)) that is not used by any current guidelines (Fig. 1). We designed this new phenotype to identify hypolipidemic patients not on lipid-lowering treatment, who have genetic disorders in apoB-containing lipoprotein particle formation. Type VI patients can include Abetalipoproteinemia $(A B L)$ due to mutations in the microsomal transfer protein, and Homozygous hypobetalipoproteinemia (HHBL) due to structural mutations in apoB. Both disorders lead to severely impaired chylomicron formation and malabsorption of fat-soluble vitamins. These patients should be treated with high dose Vitamin A and E to prevent vision loss and other neurological problems [27]. Individuals with more benign disorders of low apoB, who usually do not develop fat soluble vitamin deficiencies, such as patients with Familial Hypobetalipoproteinemia (FHBL) due to heterozygous mutations in apoB or Familial Combined Hypolipidemia due to mutations in ANGPTL3, can also have low NonHDL-C and TG, but they usually have values outside the range we used to define Type VI [28].

To characterize the lipoprotein profile of subjects classified into our new lipoprotein phenotypes, we performed NMR analysis on patients $(\mathrm{N}=11,365)$ that underwent routine diagnostic testing at the clinical laboratory at the $\mathrm{NIH}$. Each patient was first classified into their lipoprotein phenotype by plotting their nonHDL-C values against TG (Fig. 2A). Each point in the plot corresponds to an individual patient and represents the concentration of cholesterol and TG that are contained within the different types of apoB-containing lipoproteins present in a sample. The 3 dotted lines in Fig. $2 \mathrm{~A}$ correspond to the typical cholesterolto-TG ratio for purified LDL, VLDL or chylomicrons [2]. As TRL particles undergo TG loss via lipolysis and gain cholesterol from cholesteryl ester transfer protein (CETP)-mediated lipid exchange[29], they transition from the lower right corner of the plot (TG-enriched) to the upper left corner (cholesterol-enriched). Note that even for the Type I phenotype, all points fall well above the dotted line representing pure chylomicrons. Although Type I patients have relatively high levels of chylomicrons compared to other phenotypes, they still have a greater number of LDL and VLDL particles, which causes their position on the graph to shift above the pure chylomicron line. Similarly, most patients with Type lla, with an increase in cholesterol-enriched LDL particles, mostly fall to the right and below the dotted line representative of pure LDL because they also contain other types of lipoprotein particles, such as VLDL that are more enriched in TG.

To better visualize the Type VI phenotype, we plotted NonHDL-C versus the natural log of TG (Fig. 2B) and also the natural log of NonHDL-C versus the natural log of TG (Fig. 2C). Out of the 34 patient samples identified as having the Type VI phenotype, we were able to confirm that 33 of them came from either 3 different $A B L$ patients, with undetectable apoB ( $<10 \mathrm{mg} / \mathrm{dL}$ ), or from 4 different $\mathrm{HHBL}$ patients, who all had an apoB $<13 \mathrm{mg} / \mathrm{dL}$. One patient identified as Type VI, however, had Familial Combined Hypolipidemia, with an apoB of $34 \mathrm{mg} / \mathrm{dL}$. Thus, apoB testing is recommended to confirm the diagnosis of $\mathrm{ABL}$ or $\mathrm{HHBL}$ in all Type VI patients.

To facilitate the visualization of phenotype frequencies and how they relate to each other metabolically, the concentrations of NonHDL-C and TG were converted into percentiles (Fig. 2D). Most of the plot is occupied by the 3 normolipidemic phenotypes, whereas all the abnormal phenotypes fall into two peripheral zones. The most extreme phenotypes with elevated NonHDL-C or TG or both greater than at least the 97.5 th percentile fall along the most extreme top and right edges of the graph. On the top edge where NonHDL-C is the highest are the locations of the Type Ila and Ilb phenotypes. Along the right edge of the plot where TG is the highest are the Type I and V phenotypes. The two mixed dyslipoproteinemias, Type Ilb and V, fall in the top right corner of the plot where both NonHDL-C and TG are simultaneously elevated. Just inside the most extreme lipoprotein phenotypes are the $\mathrm{N}_{\mathrm{H}}$, Type IVb and Type IVa 
phenotypes, which have more intermediate elevations of NonHDL-C and or TG that are between the 85th and 97.5th percentile. Among all of the abnormal phenotypes, Type IV is by far the most common (Fig. 2D), particularly Type IVb (8.3\% in NIH database) (Table 1). When we examined a more general population from NHANES (Table 1), Type IVb was even more common at $12.5 \%$ of the total population. It is also worth noting that Type IIb was slightly more frequent in NHANES than Type Ila (2.1 vs 1.6\%). Both Type I and VI are very rare phenotypes; no one with Type I was detected in NHANES and only two with Type VI. Out of the 20 samples in the NIH database that we identified as having Type I, 18 came from 4 different patients diagnosed with lipodystrophy, a known cause of hyperchylomicronemia[30].

Table 1

Frequency of phenotypes and mean lipid

\begin{tabular}{|c|c|c|c|c|c|c|c|c|c|c|c|c|c|c|}
\hline Phenotypes & $\begin{array}{l}\mathrm{NIH} \\
(\mathrm{N}= \\
11,365)\end{array}$ & $\begin{array}{l}\text { NHANES } \\
\left(\begin{array}{l}N= \\
13,086)\end{array}\right.\end{array}$ & TC & & TG & & HDL-C & & LDL-C & & NonHDL-C & & ApoB & \\
\hline $\mathrm{N}_{\mathrm{L}}$ & $\begin{array}{l}1600 \\
(14.1 \%)\end{array}$ & $\begin{array}{l}1004 \\
(7.7 \%)\end{array}$ & $\begin{array}{l}126(112- \\
139)\end{array}$ & $\mathrm{G}^{*}$ & $\begin{array}{l}84(57- \\
110)\end{array}$ & $\mathrm{H}$ & $\begin{array}{l}53(40- \\
65)\end{array}$ & B & $\begin{array}{l}56(49- \\
64)\end{array}$ & G & $\begin{array}{l}73(65- \\
81)\end{array}$ & G & $\begin{array}{l}63(55- \\
70)\end{array}$ & G \\
\hline $\mathrm{N}_{\mathrm{M}}$ & $\begin{array}{l}7455 \\
(65.6 \%)\end{array}$ & $\begin{array}{l}8742 \\
(66.8 \%)\end{array}$ & $\begin{array}{l}180(160- \\
201)\end{array}$ & $E$ & $\begin{array}{l}91(66- \\
117)\end{array}$ & G & $\begin{array}{l}56(45- \\
67)\end{array}$ & A & $\begin{array}{l}106(89- \\
123)\end{array}$ & $E$ & $\begin{array}{l}124(106- \\
143)\end{array}$ & $E$ & $\begin{array}{l}94(82- \\
106)\end{array}$ & E \\
\hline $\mathrm{N}_{\mathrm{H}}$ & $\begin{array}{l}370 \\
(3.3 \%)\end{array}$ & $\begin{array}{l}703 \\
(5.4 \%)\end{array}$ & $\begin{array}{l}251(239- \\
262)\end{array}$ & C & $\begin{array}{l}104(80- \\
128)\end{array}$ & $\mathrm{F}$ & $\begin{array}{l}58(49- \\
68)\end{array}$ & A & $\begin{array}{l}172(165- \\
178)\end{array}$ & C & $\begin{array}{l}192(185- \\
199)\end{array}$ & C & $\begin{array}{l}137 \\
(129- \\
144)\end{array}$ & C \\
\hline 1 & $20(0.2 \%)$ & $0(0 \%)$ & $\begin{array}{l}121(113- \\
128)\end{array}$ & FG & $\begin{array}{l}577(535- \\
618)\end{array}$ & B & $\begin{array}{l}20(12- \\
29)\end{array}$ & $F$ & $\begin{array}{l}-15(-26- \\
4)\end{array}$ & 1 & $\begin{array}{l}100(93- \\
107)\end{array}$ & $\mathrm{F}$ & $\begin{array}{l}80(68- \\
92)\end{array}$ & $\mathrm{F}$ \\
\hline Ila & $\begin{array}{l}166 \\
(1.5 \%)\end{array}$ & $\begin{array}{l}205 \\
(1.6 \%)\end{array}$ & $\begin{array}{l}313(280- \\
346)\end{array}$ & A & $\begin{array}{l}108(76- \\
139)\end{array}$ & $\mathrm{F}$ & $\begin{array}{l}56(46- \\
66)\end{array}$ & $A B$ & $\begin{array}{l}235(206- \\
265)\end{array}$ & A & $\begin{array}{l}257(230- \\
283)\end{array}$ & A & $\begin{array}{l}176 \\
(158- \\
194)\end{array}$ & A \\
\hline Ilb & $\begin{array}{l}153 \\
(1.3 \%)\end{array}$ & $\begin{array}{l}274 \\
(2.1 \%)\end{array}$ & $\begin{array}{l}312(279- \\
345)\end{array}$ & A & $\begin{array}{l}292(230- \\
354)\end{array}$ & C & $\begin{array}{l}47(38- \\
56)\end{array}$ & C & $\begin{array}{l}206(181- \\
231)\end{array}$ & B & $\begin{array}{l}265(236- \\
293)\end{array}$ & A & $\begin{array}{l}181 \\
(162- \\
200)\end{array}$ & A \\
\hline IVa & $\begin{array}{l}483 \\
(4.2 \%)\end{array}$ & 391 (3\%) & $\begin{array}{l}141(123- \\
159)\end{array}$ & $\mathrm{F}$ & $\begin{array}{l}245(203- \\
286)\end{array}$ & E & $\begin{array}{l}36(27- \\
45)\end{array}$ & E & $\begin{array}{l}56(39- \\
72)\end{array}$ & G & $\begin{array}{l}105(91- \\
119)\end{array}$ & $\mathrm{F}$ & $\begin{array}{l}80(68- \\
92)\end{array}$ & $\mathrm{F}$ \\
\hline IVb & $\begin{array}{l}940 \\
(8.3 \%)\end{array}$ & $\begin{array}{l}1642 \\
(12.5 \%)\end{array}$ & $\begin{array}{l}206(187- \\
225)\end{array}$ & D & $\begin{array}{l}260(208- \\
312)\end{array}$ & D & $\begin{array}{l}39(32- \\
46)\end{array}$ & D & $\begin{array}{l}115(97- \\
132)\end{array}$ & $\mathrm{D}$ & $\begin{array}{l}167(150- \\
183)\end{array}$ & $\mathrm{D}$ & $\begin{array}{l}120 \\
(107- \\
133)\end{array}$ & D \\
\hline V & $\begin{array}{l}144 \\
(1.3 \%)\end{array}$ & $\begin{array}{l}123 \\
(0.9 \%)\end{array}$ & $\begin{array}{l}261(209- \\
314)\end{array}$ & B & $\begin{array}{l}686(580- \\
792)\end{array}$ & A & $\begin{array}{l}32(24- \\
40)\end{array}$ & $\mathrm{EF}$ & $\begin{array}{l}92(43- \\
142)\end{array}$ & $\mathrm{F}$ & $\begin{array}{l}229(182- \\
277)\end{array}$ & B & $\begin{array}{l}144 \\
(114- \\
173)\end{array}$ & B \\
\hline VI & $34(0.3 \%)$ & $2(0 \%)$ & $50(43-58)$ & $\mathrm{H}$ & $16(13-19)$ & I & $\begin{array}{l}28(24- \\
32)\end{array}$ & $\mathrm{EF}$ & $\begin{array}{l}19(15- \\
23)\end{array}$ & $\mathrm{H}$ & $\begin{array}{l}22 \\
25)\end{array}$ & $\mathrm{H}$ & $\begin{array}{l}29 \\
34)\end{array}$ & $\mathrm{H}$ \\
\hline
\end{tabular}

A limitation of our new classification method is its inability to identify Type III dyslipidemia, because of their variable NonHDL-C and TG values that overlap with the other phenotypes. Applying to the NIH database, the NonHDL-C/apoB $>4.91 \mathrm{mmol} / \mathrm{g}$ rule[31], which was recently shown to be more specific than the Sniderman rule of TC/apoB $>6.2 \mathrm{mmol} / \mathrm{g}$ for identifying Type III[10], we identified a total of 41 Type III patients, approximately $0.4 \%$ of our population. Most Type III patients fell into regions of the plot corresponding to Type IVb and V, but they also overlapped with some of the other phenotypes (Fig. 3). We also identified 98 Type III patients by a combination of agarose gel electrophoresis and beta-quantitation from patients $(\mathrm{N}=5602)$ at the Mayo Clinic. These 98 Type III patients based on their NonHDL-C and TG values had the following phenotypes by the new classification system: Type IIb 33, Type IVb 23, Type IVa 2, Type V 40. Hence, when a patient presents with clinical features, such as palmar xanthomas, or a history consistent with Type III, additional testing, such as apoB or agarose gel electrophoresis, will be necessary to confirm the diagnosis.

\section{Validation Of New Method For Lipoprotein Phenotype Classification}

The lipid values for our phenotypes are shown in Table 1 and match what would be expected for the classic Fredrickson phenotypes, but we further validated our new classification system by comparing their NMR lipoprotein profile (Fig. 4). Type Ila and IIb had a similarly high level of total LDL-particles (LDL-P), but Type lla had higher LDL-C concentrations (Table 1). This can also be seen when LDL related parameters were plotted as a contour plot (Fig. 5). Type lla followed by the $N_{H}$ phenotype had the highest level of large LDL particles, which have a greater cholesterol carrying capacity than small LDL (Fig. 4, 5). In contrast, Type Ilb patients had the highest concentration of small LDL particles, followed by Type $\mathrm{V}$ and IVb (Fig. 4, 5). In general, all of the high TG phenotypes 
had a relatively high percent of small LDL particles. This is consistent with the well-known phenomenon of CETP-mediated lipid exchange and subsequent TG lipolysis resulting in the formation of small dense LDL particles [32, 33].

Total TRL-particles (TRL-P) were the highest in Type V followed by IIb and I. Type I had the greatest number of large TRL particles (Fig. 6), most likely due to delayed clearance of chylomicrons, which are the most enriched in TG. Many of the TRL particles in Type V were smaller, consistent with having undergone partial lipolysis, as has been previously reported [34]. Small size VLDL particles in the range of 24-29 nM, which are sometimes referred to as Intermediate-Density Lipoproteins (IDL) particles, or VLDL- remnants or simply as remnants were by far the highest in Type IIb (Fig. 6). The mean ApoB level was also the highest in Type IIb (Table 1) but also increased in Type Ila (Fig. 5). Type IVb patients had an intermediate phenotype; they had considerably more TRL-P compared to the $N_{M}$ phenotype, but fewer TRL-P than Type V or Ilb. Type IVb patients also had more IDL (Fig. 6) and small LDL particles (Fig. 4) compared to the $N_{M}$ and $N_{L}$ phenotypes. The Type IVa phenotype had fewer overall TRL-particles than Type IVb except for medium and large TRL particles, which were similar in both phenotypes. The Type IVa phenotype also had less total LDL-P than most of the other hyperlipidemic phenotypes except for Type I (Fig. 4A). In terms of HDL, all of the high TG phenotypes (I, IIb, IVa, IVb and V) were low in HDL-C (Table 1) and contained more small HDL particles (Fig. 7). In summary, differences in the NMR lipoprotein profile between the different phenotypes are consistent with their known underlying metabolic defects and what has been previously observed by other lipoprotein subfractionation methods.

In Table 2, we further validated the new lipoprotein phenotyping method by comparing it a combination of agarose gel electrophoresis and beta-quantification (gel-lipid method) on patients $(N=5,602)$ tested at the Mayo Clinic. For the 3 new normolipidemic phenotypes $\left(\mathrm{N}_{\mathrm{H}}, \mathrm{N}_{\mathrm{M}}\right.$, and $\mathrm{N}_{\mathrm{L}}$ ), the two lipoprotein classification systems showed over $90 \%$ concordance. In the case of the $\mathrm{N}_{\mathrm{H}}$ phenotype, we scored mild Type Ila by the gel-lipid method as equivalent, because they have nearly identical selection criteria (see methods). There was only one Type I case identified by the new classification method, but it was scored as Type V by the gel-lipid system. All 530 patients identified as Type lla by the new classification method were classified the same way by the gel-lipid method. In the case of Type Ilb by the new classification method, approximately one quarter of the cases $(\mathrm{N}=$ 121/416) were discordantly classified as Type lla by the gel-lipid method. Although TG concentrations were significantly lower for these discordant cases compared to concordant Type Ilb cases $(205 \pm 34 \mathrm{mg} / \mathrm{dL}$ vs. $296 \pm 77$; $\mathrm{p}<0.001)$, all of the Type Ila discordant cases had TG $\geq 175 \mathrm{mg} / \mathrm{dL}$, causing them to be classified as Type llb by the new classification method, which is more consistent with how hypertriglyceridemia is currently defined by the 2018-Multisociety Guideline [1]. All of the remaining discordant cases that were classified as Type IV by the gel-lipid method $(\mathrm{N}=19)$ had NonHDL-C > $220 \mathrm{mg} / \mathrm{dL}$ but also had relatively low levels of LDL-C as measured by beta-quantification, which accounts for the differences in the two classifications. Given that it is now generally recommended by current guidelines to use NonHDL-C rather than LDL-C as an ASCVD biomarker when TG is elevated, these discordant cases are also perhaps best considered as Type Ilb, which again is more congruent with the new classification method. 
Table 2

Comparison of new lipoprotein phenotype clas

Proposed Gel-Lipid Phenotypes

Phenotypes

TG TG

$\mathrm{N}_{\mathrm{L}}$

268

$\%$ Concordance Mean Min

Total

N $\quad$ Total Concordance Mean Min

Normal

$252 \quad 94$

$86 \pm \quad 30$

26

Mild Type IV

$16 \quad 6$

168

160

Hyperlipoproteinemia

$\mathrm{N}_{\mathrm{M}}$

1624

94

$89 \pm \quad 26$
30

Normal

$1521 \quad 93.7$

$85 \pm \quad 26$

27

Mild Type IV

26

1.6

169

Hyperlipoproteinemia

Mild Type Ilb

Hyperlipoproteinemia

11

0.7

Mild Type Ila

66

4.1

Hyperlipoproteinemia

$\mathrm{N}_{\mathrm{H}}$

702

93

$\pm 5$

$170 \quad 162$

$\pm 4$

116

$\pm 34$

53

$113 \quad 34$

$\pm 32$

Mild Type Ila

Hyperlipoproteinemia

655

93.3

$112 \quad 34$

$\pm 31$

Type Ila

Hyperlipoproteinemia

45

6.4

122

$\pm 32$

62

Mild Type Ilb

2

Hyperlipoproteinemia

1

0

614

614

Type V

1

173

$\pm 1$

172

Hyperlipoproteinemia 
Proposed Gel-Lipid Phenotypes

TG

TG

Phenotypes

N $\quad \begin{aligned} & \text { Total } \\ & \text { Concordance Mean Min }\end{aligned}$

Ila

Type lla

Hyperlipoproteinemia

530

$$
100
$$

113

32

$\pm 33$

$530 \quad 100$

113

$\pm 33$

IIb

416

100

$282 \quad 175$

$\pm 87$

Type llb

Hyperlipoproteinemia

Type lla

Hyperlipoproteinemia

\section{Type IV}

Hyperlipoproteinemia

IVa

Mild Type IV

Hyperlipoproteinemia

Type V

Hyperlipoproteinemia

IVb

Type IV

Hyperlipoproteinemia

Mild Type Ilb

Hyperlipoproteinemia

Mild Type lla

Hyperlipoproteinemia

Type lla

Hyperlipoproteinemia
$276 \quad 66.3$

354

99

296

$\pm 77$

$121 \quad 29.1$

19

4.6

205

$\pm 34$

436

$\pm 41$

227
+51

$353 \quad 99.7$

$1 \quad 0.3$

1281

100

260

$\pm 72$

$226 \quad 175$

$\pm 50$

$382 \quad 382$

629

49.1

278

$\pm 81$

558

43.6

246

$\pm 58$

91

7.1

$206 \quad 175$

$\pm 34$

3

0.2

179

$\pm 3$
175

175

175

(7)

177 
Proposed Gel-Lipid Phenotypes

TG

TG

Phenotypes

\begin{tabular}{|c|c|c|c|c|c|c|}
\hline & \\
\hline & & $\mathbf{N}$ & $\begin{array}{l}\% \\
\text { Total }\end{array}$ & Concordance & Mean & Min \\
\hline \multirow[t]{5}{*}{ V } & & 328 & & 98 & $\begin{array}{l}1791 \\
\pm \\
1560\end{array}$ & 502 \\
\hline & $\begin{array}{l}\text { Type V } \\
\text { Hyperlipoproteinemia }\end{array}$ & 218 & 66.5 & & $\begin{array}{l}2424 \\
\pm \\
1622\end{array}$ & 588 \\
\hline & $\begin{array}{l}\text { Type IV } \\
\text { Hyperlipoproteinemia }\end{array}$ & 84 & 25.6 & & $\begin{array}{l}719 \\
\pm 279\end{array}$ & 502 \\
\hline & $\begin{array}{l}\text { Type llb } \\
\text { Hyperlipoproteinemia }\end{array}$ & 21 & 6.4 & & $\begin{array}{l}652 \\
\pm 171\end{array}$ & 503 \\
\hline & $\begin{array}{l}\text { Type I } \\
\text { Hyperlipoproteinemia }\end{array}$ & 5 & 1.5 & & $\begin{array}{l}4545 \\
\pm \\
2459\end{array}$ & 2745 \\
\hline
\end{tabular}

Type IVb cases by the new classification were discordantly scored about half the time as either mild Type llb, mild Type Ila or as Type lla by the gel-lipid method. All of these discordant cases had higher levels of NonHDL-C than the concordant Type IV cases (Table 2), but nevertheless had NonHDL-C levels below $220 \mathrm{mg} / \mathrm{dL}$ and TG $\geq 175 \mathrm{mg} / \mathrm{dL}$, leading them to be categorized as Type IVb by the new classification system. Type IVa cases by the new method were classified as mild Type IV by the gel-lipid method in $99 \%$ of cases, which can be considered equivalent based on their similar selection criteria (see methods). Finally, Type V cases were concordant in 59\% (218/328) of cases. The discordant cases were mostly classified as Type IV $(84 / 328)$ based on the lack of abundant chylomicrons near the origin of the gel, which can also be an artifact from loss of these large lipoprotein particles from the loading of the gel during electrophoresis. Some of the discordant Type Ilb (21/328) had TG $\geq 500 \mathrm{mg} / \mathrm{dL}$, and therefore, are probably best reconsidered as Type $V$, according to current guidelines because of their increased risk for pancreatitis. In summary, several of the seemingly discordant cases mostly differed in only their name and not their selection criteria ( $\mathbf{N}_{\mathrm{H}}$ vs. mild lla, Type IVb vs. mild IV). In other instances, discordance was likely due to a combination of subtle differences in the qualitative interpretation of the lipoprotein patterns on the agarose gels and to differences in the type of criteria used over the years for classifying patients into the different Fredrickson phenotypes (qualitative vs quantitative, percentile vs absolute concentration units, NonHDL-C vs LDL-C, different TG cut-points)[35]. When the remaining discordant cases between the new classification method and the gel-lipid method were reclassified based on their plasma TG level, using currently recommended TG-cutpoints, it 


\section{leads to greater than $90 \%$ concordance for the two classifications for almost all of the phenotypes (Table 2).}

\section{Association Of Lipoprotein Phenotypes With Ascrd}

We investigated the association of the different phenotypes by the new classification system with other risk factors in the MESA cohort, except for Type I, which was not present in this population (Table 3). As would be expected, because elevated TG is one of the criteria for metabolic syndrome, we found that metabolic syndrome was strongly associated with all of the high TG phenotypes. Other features seen with metabolic syndrome that can increase ASCVD risk, such as diabetes, increased BMI and elevated systolic blood pressure, were also associated with some of the high TG phenotypes, but these associations were not as strong. Differences in C-Reactive Protein (CRP) levels between the phenotypes were relatively small or insignificant. African American males and females comprised $28 \%$ of the total population in MESA, but they were about half as frequent in the high TG phenotypes but were more likely to be in the $\mathrm{N}_{\mathrm{L}}$ and Ila phenotypes (Table 3). Gender was almost equally distributed among the various phenotypes. 
Table 3

Association of phenotypes with ASCVD risk factors

\begin{tabular}{|c|c|c|c|c|c|c|c|c|c|c|c|}
\hline Level & Number & $\begin{array}{l}\text { Mean } \\
\text { Age }\end{array}$ & $\begin{array}{l}p= \\
0.0049\end{array}$ & Mean BMI & $\begin{array}{l}P< \\
0.0001\end{array}$ & Mean SBP & $\begin{array}{l}P= \\
0.0011\end{array}$ & Mean CRP & $\begin{array}{l}P= \\
0.0097\end{array}$ & & \\
\hline $\mathrm{N}_{\mathrm{L}}$ & 246 & $\begin{array}{l}63(54- \\
72)\end{array}$ & $A$ & $\begin{array}{l}28(23.9- \\
32.1)\end{array}$ & $\mathrm{C}$ & $\begin{array}{l}124(109- \\
140)\end{array}$ & $\mathrm{D}$ & $3.8(1.8-5.8)$ & $\mathrm{BC}$ & & \\
\hline $\mathrm{N}_{\mathrm{M}}$ & 4632 & $\begin{array}{l}62(53- \\
71)\end{array}$ & $A$ & $\begin{array}{l}28(24.7- \\
31.4)\end{array}$ & C & $\begin{array}{l}126(112- \\
141)\end{array}$ & $C D$ & $3.7(2.0-5.3)$ & C & & \\
\hline $\mathrm{N}_{\mathrm{H}}$ & 424 & $\begin{array}{l}62(54- \\
69)\end{array}$ & $A B C$ & $\begin{array}{l}28.5(25.5- \\
31.5)\end{array}$ & $\mathrm{BC}$ & $\begin{array}{l}127(113- \\
140)\end{array}$ & $\mathrm{BCD}$ & $3.3(1.7-4.9)$ & C & & \\
\hline Ila & 91 & $\begin{array}{l}62(53- \\
70)\end{array}$ & $A B C$ & $\begin{array}{l}27.7(24.9- \\
30.6)\end{array}$ & C & $\begin{array}{l}126(111- \\
141)\end{array}$ & $A B C D$ & $3.4(1.6-5.2)$ & $\mathrm{BC}$ & & \\
\hline Ilb & 177 & $\begin{array}{l}62(54- \\
69)\end{array}$ & $A B C$ & $\begin{array}{l}29.4(26.5- \\
32.3)\end{array}$ & $A B$ & $\begin{array}{l}129(115- \\
143)\end{array}$ & $A B C$ & $3.7(2.1-5.3)$ & $\mathrm{BC}$ & & \\
\hline IVa & 144 & $\begin{array}{l}62(54- \\
70)\end{array}$ & $A B$ & $\begin{array}{l}30(27.2- \\
32.9)\end{array}$ & $A$ & $\begin{array}{l}132(117- \\
146)\end{array}$ & A & $5.2(2.1-8.4)$ & A & & \\
\hline $\mathrm{IVb}$ & 1040 & $\begin{array}{l}61(53- \\
69)\end{array}$ & $\mathrm{BC}$ & $\begin{array}{l}29.4(26.3- \\
32.5)\end{array}$ & $A$ & $\begin{array}{l}129(115- \\
142)\end{array}$ & $A B$ & $4.2(2.4-5.9)$ & $\mathrm{BC}$ & & \\
\hline V & 34 & $\begin{array}{l}58(53- \\
63)\end{array}$ & C & $\begin{array}{l}29.1(25.8- \\
32.4)\end{array}$ & $A B C$ & $\begin{array}{l}131(116- \\
147)\end{array}$ & $A B C D$ & $4(1.6-6.3)$ & $A B C$ & & \\
\hline Level & Number & $\% A A$ & $\begin{array}{l}\mathrm{P}< \\
0.0001\end{array}$ & $\begin{array}{l}\% \text { with } \\
\text { diabetes }\end{array}$ & $\begin{array}{l}P< \\
0.0001\end{array}$ & $\begin{array}{l}\% \text { on } \mathrm{BP} \\
\text { meds }\end{array}$ & $\begin{array}{l}p< \\
0.0001\end{array}$ & $\begin{array}{l}\% \text { with Metabolic } \\
\text { Syndrome }\end{array}$ & $\begin{array}{l}p< \\
0.0001\end{array}$ & $\begin{array}{l}\% \text { of } \\
\text { Smokers }\end{array}$ & $\begin{array}{l}p= \\
0.0002\end{array}$ \\
\hline $\mathrm{N}_{\mathrm{L}}$ & 246 & $41.1 \%$ & $A$ & $31.7 \%$ & $\mathrm{BC}$ & $49.6 \%$ & A & $31.7 \%$ & D & $19.9 \%$ & $A B$ \\
\hline $\mathrm{N}_{\mathrm{M}}$ & 4632 & $31.0 \%$ & B & $23.1 \%$ & $\mathrm{D}$ & $36.4 \%$ & D & $24.7 \%$ & $E$ & $13.5 \%$ & C \\
\hline $\mathrm{N}_{\mathrm{H}}$ & 424 & $31.1 \%$ & B & $23.6 \%$ & $\mathrm{D}$ & $29.0 \%$ & $E$ & $26.4 \%$ & $\mathrm{DE}$ & $15.8 \%$ & $\mathrm{BC}$ \\
\hline Ila & 91 & $39.6 \%$ & $A B$ & $28.6 \%$ & CD & $23.1 \%$ & $E$ & $25.3 \%$ & $\mathrm{DE}$ & $15.4 \%$ & $\mathrm{BC}$ \\
\hline Ilb & 177 & $11.3 \%$ & $C D$ & $39.0 \%$ & $\mathrm{BC}$ & $40.1 \%$ & $\mathrm{BCD}$ & $76.3 \%$ & $\mathrm{BC}$ & $16.9 \%$ & $\mathrm{BC}$ \\
\hline IVa & 144 & $20.8 \%$ & C & $40.3 \%$ & B & $49.3 \%$ & $A B$ & $84.7 \%$ & $A B$ & $20.1 \%$ & $A B$ \\
\hline $\mathrm{IVb}$ & 1040 & $11.3 \%$ & $\mathrm{D}$ & $36.1 \%$ & $\mathrm{BC}$ & $40.2 \%$ & $\mathrm{C}$ & $76.8 \%$ & $\mathrm{C}$ & $17.1 \%$ & B \\
\hline V & 34 & $14.7 \%$ & $C D$ & $67.6 \%$ & $A$ & $41.2 \%$ & $A B C D E$ & $94.1 \%$ & $A$ & $32.4 \%$ & $A$ \\
\hline Level & Number & $\%$ Male & $\begin{array}{l}p= \\
0.3353\end{array}$ & & & & & & & & \\
\hline $\mathrm{N}_{\mathrm{L}}$ & 246 & $46.3 \%$ & $A$ & & & & & & & & \\
\hline $\mathrm{N}_{\mathrm{M}}$ & 4632 & $46.5 \%$ & $A$ & & & & & & & & \\
\hline $\mathrm{N}_{\mathrm{H}}$ & 424 & $46.9 \%$ & A & & & & & & & & \\
\hline Ila & 91 & $42.9 \%$ & $A$ & & & & & & & & \\
\hline llb & 177 & $46.9 \%$ & A & & & & & & & & \\
\hline IVa & 144 & $48.6 \%$ & $A$ & & & & & & & & \\
\hline $\mathrm{IVb}$ & 1040 & $50.9 \%$ & A & & & & & & & & \\
\hline V & 34 & $52.9 \%$ & $A$ & & & & & & & & \\
\hline
\end{tabular}

Next, we performed ASCVD survival curve analysis for the different phenotypes in ARIC instead of MESA because of its larger size and longer follow-up period (Fig. 8). To simplify the plot, the 3 normolipidemic phenotypes were initially combined and Type I was excluded because of its small sample size ( $\mathrm{N}=2$ ). Type $\mathrm{V}$ had the highest rate of ASCVD events, followed by Type Ilb and IVb, which were nearly equal, and then Type Ila and IVa and finally the normolipidemic phenotypes (Fig. 8A). In Fig. 8B, we separated the three normolipidemic phenotypes and found as expected that $\mathrm{N}_{\mathrm{H}}$ showed greater risk than the $\mathrm{N}_{\mathrm{M}}$ and $\mathrm{N}_{\mathrm{L}}$ which overlapped. The $\mathrm{N}_{\mathrm{H}}$ survival curve also overlapped with the curve for the Type IVa phenotype. Finally, we did survival curve analysis for Metabolic Syndrome and found that several of the dyslipidemic phenotypes (Type Ilb, IVb and V) had a similar if not a stronger association with ASCVD than Metabolic Syndrome (Fig. 8C, Supplemental Table 1). This suggests that like Metabolic Syndrome the high-risk lipoprotein phenotypes could potentially be used prognostically as risk enhancer conditions for those patients at intermediate risk as determined by the 10-year risk calculator [1].

\section{Discussion}


Our new lipoprotein phenotyping method (1) enables the classification of all dyslipidemias except for Type III, using standard lipid panel test results, (2) demonstrates an association between some of the lipoprotein phenotypes with ASCVD risk factors, such as diabetes and metabolic syndrome, and (3) revealed for several of the phenotypes a strong association with ASCVD events and hence could be used as risk enhancer conditions. Moreover, new lipoprotein phenotypes could potentially be automated and reported by clinical laboratories on all patients with a standard lipid panel. This may be especially valuable in identifying patients with high-risk mixed dyslipidemias, who are often missed or under-treated[36]. The overall genetic, prognostic, diagnostic and therapeutic implications for the different lipoproteins phenotypes and how this information can help guide clinical management are described below and in Table 4.

When the Fredrickson classification was first developed, one early hypothesis was that the different lipoprotein phenotypes were due to distinct monogenic mutations, but this is not the case for most phenotypes (Table 4). Even in the case of Familial Hypercholesterolemia (FH) with the Type lla phenotype for which there are known causal monogenic mutations in the LDL-receptor gene or related genes, most patients with the Type lla have polygenic hypercholesterolemia [37]. In addition, the lipoprotein phenotype unlike the genotype is not invariant and can change in response to drug therapy and environmental factors, such as diet and physical activity. Nevertheless, establishment of the lipoprotein phenotype may help focus the management of hyperlipidemia [38]. For example, although secondary causes, such as obesity and diabetes, are in general associated with dyslipidemias, several of the secondary causes listed in Table 4 are more specific for certain phenotypes. As described in Table 4, secondary causes should always be considered when first evaluating a patient. Secondary causes can frequently be uncovered by a careful patient history and physical exam and when addressed can often resolve the dyslipidemia.

In terms of primary causes, the more stringent criteria that we applied for identifying Type lla and some of the other phenotypes than the Sniderman classification should enable a more targeted identification of patients with monogenic mutations. Once the more common secondary causes are excluded, genetic testing of Type lla patients to identify specific pathogenic mutations ( $L D L R, A P O B, L D L R A P 1, P C S K 9)$ can be considered, depending on the LDL-C level (Table 4) and can help inform family cascade screening[23]. Patients with extreme elevations of TG (Type I and V) can also have specific pathogenic mutations (e.g. LPL, APOC2, GPIHBP1, LMF1, APOA5)[39]. Type V patients, however, who typically present in adulthood with dyslipidemia, are more likely to have multifactorial chylomicronemia with one or more secondary causes, such as uncontrolled diabetes[40]. Polygenic risk scores for both hypercholesterolemia[37] and hypertriglyceridemia[41] have also been described, but their clinical utility is still being investigated. As we do in Table 4 and as recommend by others[42], the designation "Familial" is perhaps best reserved for those cases in which a primary monogenic cause or genotype has been established by DNA sequencing or biochemical testing. Otherwise, the phenotypes can either be referred to by their traditional Roman numeral designations as we did or alternatively by the more generic descriptive terms shown in Table 4 in order to avoid confusion between genotype and phenotype.

Another value to the lipoprotein phenotyping is related to their prognosis and need for referral to a medical specialist. In the cases of Type I and $\mathrm{V}$, referral to a lipid specialist and nutritionist is highly recommended for preventing pancreatitis[43]. It has been shown that patients with markedly elevated TG often have poor follow-up [44]. Identifying such patients by lipoprotein phenotyping, followed by specific and appropriate treatment can reduce the incidence of acute pancreatitis [45] In case of Type I, referral to a nutritionist is important because adherence to a strict low-fat diet is challenging but often necessary as pharmacotherapy often does not add much benefit when lipoprotein lipase activity is very low or nonexistent [34]. Because of the high incidence of ASCVD in patients with Type Ila, IIb, and III phenotypes [12,33], and their frequent need for combination pharmacotherapy[46], many of these patients should be seen by a lipid specialist, particularly if they do not show a good response to initial therapy. Type VI patients should not only be referred to a lipid specialist but also to a nutritionist for instructions on a low-fat diet and for high-dose fat soluble vitamin supplementation. They may also need additional referrals to an ophthalmologist and neurologist to monitor and or treat the other clinical manifestations of their disorder.

Lipoprotein phenotyping also has diagnostic testing implications. Because small LDL, IDL, and remnant lipoproteins, which are all considered pro-atherogenic, were found by NMR to be enriched in Type IIb, IV, and V, more in depth advance lipid testing, including the measurement of apoB, may be useful for these phenotypes (Table 4). Numerous studies have shown that when TG is elevated that LDL-C, particularly when calculated, underestimates ASCVD risk and that NonHDL-C, apoB, or LDL-P may be better suited for risk assessment $[16,17,47,48]$. Although no single pathogenic mutation has been associated with Type Ilb[36], apoB may be useful to screen Type Ilb families with a strong history of ASCVD, because it has been shown to be a better risk predictor in this population than LDL-C[16]. ApoB should also be ordered in all Type VI patients to confirm their diagnosis and whenever Type III is suspected.

In case of the $\mathrm{N}_{H}$ phenotype, we observed in NHANES that more than $75 \%$ of these patients had an apoB $\geq 130 \mathrm{mg} / \mathrm{dL}$, whereas less than $3 \%$ of $\mathrm{N}_{\mathrm{M}}$ phenotype patients did so. This suggests that ordering apoB as a risk enhancer test is less likely to be informative for the $N_{M}$ phenotype, and its main impact in the $N_{H}$ phenotype may be in identifying those patients that have lower not higher risk because of a lower-than-expected apoB value.

Because the lipid cut-points utilized by our phenotyping method are largely based on current lipid guidelines, lipoprotein phenotyping can be an aid in cardiovascular risk assessment and for improving compliance with guidelines. According to 2018-Multisociety Guidelines[1], patients with an LDL-C $\geq 190$ $\mathrm{mg} / \mathrm{dL}$, which is equivalent to Type lla in the new classification system, are considered to have sufficient risk to warrant high-intensity statin treatment without requiring calculation of their 10-year ASCVD risk. Thus, the proposed lipoprotein phenotyping method can be useful by automatically identifying and highlighting these high-risk patients. A similar argument can also be made for aggressive statin treatment of all Type Ilb patients. Presently, many Type Ilb patients may be under-treated unless their nonHDL-C is also considered because their LDL-C is often less than 190 mg/dL[36], which occurred about half the time in our study population. Consistent with what has been previously described[36], we found in ARIC that Type IIb patients had overall an equal if not greater ASCVD risk than Type lla [36, 48]. In addition, almost all of Type llb patients in our study had an apoB $\geq 130 \mathrm{mg} / \mathrm{dL}$ (96\%), a known ASCVD risk enhancer. Furthermore, they are also at increased risk because of their high TG ( $\geq 175 \mathrm{mg} / \mathrm{dL}$ ), another ASCVD risk enhancer. Based on our survival curve analysis, Type $\mathrm{V}$ and IVb patients could also be considered high risk patients and considered as risk enhancer conditions for those at intermediate risk by the 10-year ASCVD risk calculation. One group of patients for which ASCVD risk calculation is currently deemed unnecessary because of their low risk are primary prevention patients with an LDL-C $\leq 70 \mathrm{mg} / \mathrm{dL}$ Based on our classification system, this would include all $\mathrm{N}_{\mathrm{L}}$ patients.

Page 12/23 
The classification of patients into different lipoprotein phenotypes can also help direct the choice of therapy (Table 4). For Type lla and $\mathrm{N}_{\mathrm{H}}$, the primary lipid abnormality is elevated LDL-C, so statins should be the drug of first choice, if lifestyle modifications prove insufficient. In regard to TG lowering for pancreatitis prevention, fibrates and high dose omega-3 fatty acid supplementation are useful [49]. These medications, however, should always be used in conjunction with management of secondary causes of hypertriglyceridemia. Lifestyle modifications should also be recommended and can often be very effective for Type $\mathrm{V}[25,26,50]$. For many patients with Type I and some $\mathrm{V}$ patients with persistent marked hypertriglyceridemia or multiple episodes of pancreatitis, a very lowfat diet is often an essential part of therapy [46,50]. Gene therapy for LPL deficiency was approved in Europe, but it is no longer available [51]. Volanesorsen, an anti-sense oligonucleotide against ApoC-III, can lower TG even in patients with Type I from LPL deficiency[52], and is approved in Europe but not in the US[53]. For Type I patients presenting with acute pancreatitis from APOC2 gene mutations, infusion of fresh frozen plasma from normal donors containing apoC-II can be considered for rapidly lowering TG [54].

In treating more moderate forms of hypertriglyceridemia seen in Type IIb, III, and IV, reduction of dietary sugar and ethanol intake, as well as weight reduction and increased physical activity, are often very effective and recommended by current guidelines[50]. If these lifestyle measures do not sufficiently lower ASCVD risk, statin therapy should also be added, and it may have a slight benefit in also lowering TG. Statin monotherapy, however, may be insufficient, especially in cases of persistent elevations of LDL-P, small, dense LDL particles or remnant particles [33]. In these cases, full-dose omega-3 fatty acid supplementation in the form of Icosapent ethyl should be considered as it has been shown in the REDUCE-IT trial to reduce ASCVD risk on top of statins in patients with mild to moderate hypertriglyceridemia[13,55]. Fibrates or nicotinic acid could also be considered[46], but ASCVD benefit has not yet been demonstrated for these drugs in randomized clinical trials when used with statins[14,33,46,56,57]. With respect to fibrates as add-on to statins, there is only evidence from post-hoc analysis demonstrating that fenofibrates are possibly effective[58,59]. Although it is clear from genetic studies that many of the causes of hypertriglyceridemia increase the risk for $\operatorname{ASCVD}[58,60,61]$; it is not known at this time if lowering TG, in general, will translate into reduced ASCVD events[58, 62]. Finally, for Type VI patients with $A B L$ and HHBL, it is critical to treat them with high dose Vitamin A and E supplementation and sometimes other fat-soluble vitamins and essential fatty acids in order to prevent blindness, neuropathy and other clinical problems[27]. A very low-fat diet can also alleviate many of the severe gastrointestinal symptoms from fat malabsorption that almost all these patients develop.

\section{Study Strengths And Limitations}

A major strength of the study is that our new method for lipoprotein phenotyping has been validated by two different methods (NMR and agarose gel/betaquantification), in multiple populations (rare lipoprotein disorder patients and community-dwelling individuals). Another strength is the use of readily available test results (standard lipid panel), thus enabling its rapid implementation in the clinic, with very little additional costs. Furthermore, lipoprotein phenotyping by our method could potentially be automatically performed by clinical laboratory information systems on all patients tested with a standard lipid panel.

A limitation of our approach is that it cannot be used to identify Type III patients; however, Type III is relatively uncommon, and when clinically suspected, additional testing such as apoB, lipoprotein electrophoresis, or beta-quantification can be used to confirm the diagnosis. Another limitation of our method, which is also shared by other lipoprotein phenotype classification systems, is that it does not address disorders related to low HDL and elevated Lp(a). We also acknowledge that the metabolic disturbances that lead to dyslipoproteinemias occur across a continuum, leading to overlap between the phenotypes at the edges. Our lipid cut-points, therefore, are somewhat arbitrary but are almost all based on widely accepted criteria from guidelines that are already used for the management of patients.

\section{Conclusion}

The lipoprotein phenotype is not a specific diagnosis and is instead best viewed like a clinical syndrome. It encompasses a constellation of shared signs and symptoms that is not only useful in ASCVD risk assessment, but also for identifying other lipid-related diseases, directing lipid-lowering therapy, guiding further diagnostic testing and in referring patients to medical specialists. Given that almost all ASCVD drug trials and other related clinical studies will have measured a standard lipid panel, our new classification system can be easily retrospectively applied to many previously performed studies for identifying the association of dyslipidemic phenotypes with various predisposing conditions or for their response to novel drugs or other types of interventions.

\section{Declarations}

Ethics approval and consent to participate

Research under this study was considered non-human subject research and was exempted by the NIH-IRB.

Consent for publication

All authors have reviewed final manuscript and given consent for publication

Availability of data and material

De-identified clinical laboratory test results from the National Health and Nutrition Examination Survey (NHANES, 2005-2016) were used for external validation and downloaded from the following website: https://wwwn.cdc.gov/nchs/nhanes/. De-identified datasets for external validation were also obtained from the Multi Ethnic Study of Atherosclerosis (MESA) and the Atherosclerosis Risk in Communities (ARIC), using BioLINCC (https://biolincc.nhlbi.nih.gov/home/). Software developed for lipoprotein phenotyping analysis by the newly developed method can be freely downloaded at the following website: https://figshare.com/articles/software/Sampson_Phenotype_Calculator/16617490

Competing interests

Page $13 / 23$ 
No competing interests. The following disclosures apply: ATR reports research support (CRADA) to his institution from AstraZeneca, Corvidia Therapeutics and Hartis Pharmaceuticals. RSR reports research support to his institution from Amgen, Novartis and Regeneron; serves on advisory boards for Amgen, C5, CVS Caremark, Novartis. Regneron and 89 Bio; receives honoraria for non-commercial educational activities from Amgen, Kowa, and Regeneron; has stock ownership in MediMergent LLC; and receives royalties from Wolters Kluwwer (UptoDate). None of the other authors have disclosures to report.

Funding

Research by RAB, AW, SW, MA, RA and ATR is supported by intramural DIR research funds from NHLBI.

Authors' contributions

MS, JM and ATR have contributed to the design and analysis. All authors MS, RAB, DS, AW, SW, JM, LD, EF, JO, EB, RR, PW, MA, RS, SK, ATR have contributed to the writing and review of manuscript

Acknowledgements

none

\section{References}

1. Grundy SM, et al., 2018 AHA/ACC/AACVPR/AAPA/ABC/ACPM/ADA/AGS/APhA/ASPC/NLA/PCNA Guideline on the Management of Blood Cholesterol: A Report of the American College of Cardiology/American Heart Association Task Force on Clinical Practice Guidelines. Circulation, 2019. 139(25): $\mathrm{p}$. e1082-e1143.

2. Fredrickson DS, Levy RI, Lees RS, Fat transport in lipoproteins-an integrated approach to mechanisms and disorders. N Engl J Med, 1967. 276(1): p. 3442 contd.

3. Fredrickson DS, Levy RI, Lees RS, Fat transport in lipoproteins-an integrated approach to mechanisms and disorders. N Engl J Med, 1967. 276(2): p. 94103 contd.

4. Fredrickson DS, Levy RI, Lees RS, Fat transport in lipoproteins-an integrated approach to mechanisms and disorders. N Engl J Med, 1967. 276(3): p. 148 -56 contd.

5. Fredrickson DS, Levy RI, Lees RS, Fat transport in lipoproteins-an integrated approach to mechanisms and disorders. N Engl J Med, 1967. 276(4): p. 215 -25 contd.

6. Fredrickson DS, Levy RI, Lees RS, Fat transport in lipoproteins-an integrated approach to mechanisms and disorders. N Engl J Med, 1967. 276(5): p. 273 -81 concl.

7. Rosenson RS, Najera SD, Hegele RA. Heterozygous familial hypercholesterolemia presenting as chylomicronemia syndrome. J Clin Lipidol. 2017;11(1):294-6.

8. Hopkins PN, Brinton EA, Nanjee MN. Hyperlipoproteinemia type 3: the forgotten phenotype. Curr Atheroscler Rep. 2014;16(9):440.

9. Fredrickson DS. Phenotyping. On reaching base camp (1950-1975). Circulation. 1993;87(4 Suppl):III1-15.

10. Sniderman A, et al. Diagnosis of type III hyperlipoproteinemia from plasma total cholesterol, triglyceride, and apolipoprotein B. J Clin Lipidol. 2007;1(4):256-63.

11. Sniderman A, Couture P, de Graaf J. Diagnosis and treatment of apolipoprotein B dyslipoproteinemias. Nat Rev Endocrinol. 2010;6(6):335-46.

12. Brinton EA. Management of Hypertriglyceridemia for Prevention of Atherosclerotic Cardiovascular Disease. Endocrinol Metab Clin North Am. 2016;45(1):185-204.

13. Bhatt DL, et al. Cardiovascular Risk Reduction with Icosapent Ethyl for Hypertriglyceridemia. N Engl J Med. 2019;380(1):11-22.

14. Jacobson TA, et al. National lipid association recommendations for patient-centered management of dyslipidemia: part 1-full report. J Clin Lipidol. 2015;9(2):129-69.

15. Sampson M, et al. A New Equation for Calculation of Low-Density Lipoprotein Cholesterol in Patients With Normolipidemia and/or Hypertriglyceridemia. JAMA Cardiol. 2020;5(5):540-8.

16. Sniderman AD. Applying apoB to the diagnosis and therapy of the atherogenic dyslipoproteinemias: a clinical diagnostic algorithm. Curr Opin Lipidol. 2004;15(4):433-8.

17. Sniderman AD, Robinson JG. ApoB in clinical care: Pro and Con. Atherosclerosis. 2019;282:169-75.

18. Garcia E, et al. The extended lipid panel assay: a clinically-deployed high-throughput nuclear magnetic resonance method for the simultaneous measurement of lipids and Apolipoprotein B. Lipids Health Dis. 2020;19(1):247.

19. Jeyarajah EJ, Cromwell WC, Otvos JD. Lipoprotein particle analysis by nuclear magnetic resonance spectroscopy. Clin Lab Med. 2006;26(4):847-70.

20. Grundy SM, et al., Definition of metabolic syndrome: Report of the National Heart, Lung, and Blood Institute/American Heart Association conference on scientific issues related to definition. Circulation, 2004. 109(3): p. 433-8.

21. Rawla P, et al. Hypertriglyceridemia-induced pancreatitis: updated review of current treatment and preventive strategies. Clin J Gastroenterol. 2018;11(6):441-8.

22. Hansen SEJ, et al. Low-Grade Inflammation in the Association between Mild-to-Moderate Hypertriglyceridemia and Risk of Acute Pancreatitis: A Study of More Than 115000 Individuals from the General Population. Clin Chem. 2019;65(2):321-32. 
23. Migliara G, et al. Familial Hypercholesterolemia: A Systematic Review of Guidelines on Genetic Testing and Patient Management. Front Public Health. 2017;5:252.

24. Goff DC Jr, et al., 2013 ACC/AHA guideline on the assessment of cardiovascular risk: a report of the American College of Cardiology/American Heart Association Task Force on Practice Guidelines. J Am Coll Cardiol, 2014. 63(25 Pt B): p. 2935-2959.

25. Lenaerts $\mathrm{J}$, et al. Fatty liver hepatitis and type 5 hyperlipoproteinemia in juvenile diabetes mellitus. Case report and review of the literature. $\mathrm{J}$ Clin Gastroenterol. 1990;12(1):93-7.

26. Brahm AJ, Hegele RA. Combined hyperlipidemia: familial but not (usually) monogenic. Curr Opin Lipidol. 2016;27(2):131-40.

27. Welty FK. Hypobetalipoproteinemia and abetalipoproteinemia. Curr Opin Lipidol. 2014;25(3):161-8.

28. Hooper AJ, Burnett JR. Update on primary hypobetalipoproteinemia. Curr Atheroscler Rep. 2014;16(7):423.

29. Chowaniec Z, Skoczynska A. Plasma lipid transfer proteins: The role of PLTP and CETP in atherogenesis. Adv Clin Exp Med. 2018;27(3):429-36.

30. Prieur X, et al. Congenital lipodystrophies and dyslipidemias. Curr Atheroscler Rep. 2014;16(9):437.

31. Boot CS, et al. Evaluation of the Non-HDL Cholesterol to Apolipoprotein B Ratio as a Screening Test for Dysbetalipoproteinemia. Clin Chem. 2019;65(2):313-20.

32. Hirayama S, Miida T. Small dense LDL: An emerging risk factor for cardiovascular disease. Clin Chim Acta. 2012;414:215-24.

33. Stahel P, et al. The Atherogenic Dyslipidemia Complex and Novel Approaches to Cardiovascular Disease Prevention in Diabetes. Can J Cardiol. 2018;34(5):595-604.

34. Gotoda T, et al. Diagnosis and management of type I and type V hyperlipoproteinemia. J Atheroscler Thromb. 2012;19(1):1-12.

35. Sullivan DR, Lewis B. A classification of lipoprotein disorders:implications for clinical management. Clinical Lipidology. 2011;6(3):327-38.

36. Bello-Chavolla OY, et al. Familial Combined Hyperlipidemia: Current Knowledge, Perspectives, and Controversies. Rev Invest Clin. 2018;70(5):224-36.

37. Sharifi M, et al. Polygenic Hypercholesterolemia and Cardiovascular Disease Risk. Curr Cardiol Rep. 2019;21(6):43.

38. Stone NJ. Secondary causes of hyperlipidemia. Med Clin North Am. 1994;78(1):117-41.

39. Berberich AJ, Hegele RA. The role of genetic testing in dyslipidaemia. Pathology. 2019;51(2):184-92.

40. Esparza MI, et al. Very Severe Hypertriglyceridemia in a Large US County Health Care System: Associated Conditions and Management. J Endocr Soc. 2019;3(8):1595-607.

41. Dron JS, Hegele RA. Polygenic influences on dyslipidemias. Curr Opin Lipidol. 2018;29(2):133-43.

42. Brahm A, Hegele RA. Hypertriglyceridemia Nutrients. 2013;5(3):981-1001.

43. Chyzhyk V, Brown AS. Familial chylomicronemia syndrome: A rare but devastating autosomal recessive disorder characterized by refractory hypertriglyceridemia and recurrent pancreatitis. Trends Cardiovasc Med; 2019.

44. Toth PP, et al. Clinical and economic outcomes in a real-world population of patients with elevated triglyceride levels. Atherosclerosis. $2014 ; 237(2): 790-7$.

45. Sandhu S, et al. Incidence of pancreatitis, secondary causes, and treatment of patients referred to a specialty lipid clinic with severe hypertriglyceridemia:

a retrospective cohort study. Lipids Health Dis. 2011;10:157.

46. Barnett J, Viljoen A, Wierzbicki AS. The need for combination drug therapies in patients with complex dyslipidemia. Curr Cardiol Rep. $2013 ; 15(8): 391$.

47. Watson KE, et al., Advanced lipid testing: when, why, and in whom? Rev Cardiovasc Med, 2014. 15(4): p. 310-7; quiz 318-9.

48. Otvos JD, et al. Clinical implications of discordance between low-density lipoprotein cholesterol and particle number. J Clin Lipidol. 2011;5(2):105-13.

49. Brahm AJ, Hegele RA. Chylomicronaemia-current diagnosis and future therapies. Nat Rev Endocrinol. 2015;11(6):352-62.

50. Miller M, et al. Triglycerides and cardiovascular disease: a scientific statement from the American Heart Association. Circulation. 2011;123(20):2292-333.

51. Gaudet D, Methot J, Kastelein J. Gene therapy for lipoprotein lipase deficiency. Curr Opin Lipidol. 2012;23(4):310-20.

52. Gaudet D, et al. Targeting APOC3 in the familial chylomicronemia syndrome. N Engl J Med. 2014;371(23):2200-6.

53. Paik J, Duggan S, Volanesorsen: First Global Approval. Drugs, 2019.

54. Wolska A, et al. Apolipoprotein C-II: New findings related to genetics, biochemistry, and role in triglyceride metabolism. Atherosclerosis. 2017;267:49-60.

55. Orringer CE, Jacobson TA, Maki KC. National Lipid Association Scientific Statement on the use of icosapent ethyl in statin-treated patients with elevated triglycerides and high or very-high ASCVD risk. J Clin Lipidol. 2019;13(6):860-72.

56. Investigators A-H, et al. Niacin in patients with low HDL cholesterol levels receiving intensive statin therapy. N Engl J Med. 2011;365(24):2255-67.

57. Group HTC, et al. Effects of extended-release niacin with laropiprant in high-risk patients. N Engl J Med. 2014;371(3):203-12.

58. Nordestgaard BG, Varbo A. Triglycerides and cardiovascular disease. Lancet. 2014;384(9943):626-35.

59. Elam M, Lovato L, Ginsberg H. The ACCORD-Lipid study: implications for treatment of dyslipidemia in Type 2 diabetes mellitus. Clin Lipidol. 2011;6(1):920.

60. Toth PP. Triglyceride-rich lipoproteins as a causal factor for cardiovascular disease. Vasc Health Risk Manag. 2016;12:171-83.

61. Ference BA, et al. Association of Triglyceride-Lowering LPL Variants and LDL-C-Lowering LDLR Variants With Risk of Coronary Heart Disease. JAMA. 2019;321(4):364-73.

62. Jakob T, et al. Fibrates for primary prevention of cardiovascular disease events. Cochrane Database Syst Rev. 2016;11:CD009753.

63. Hegele RA, et al. The polygenic nature of hypertriglyceridaemia: implications for definition, diagnosis, and management. Lancet Diabetes Endocrinol. 2014;2(8):655-66. 
64. Goldberg AC, et al. Familial hypercholesterolemia: screening, diagnosis and management of pediatric and adult patients: clinical guidance from the National Lipid Association Expert Panel on Familial Hypercholesterolemia. J Clin Lipidol. 2011;5(3 Suppl):S1-8.

65. Sturm AC, et al. Clinical Genetic Testing for Familial Hypercholesterolemia: JACC Scientific Expert Panel. J Am Coll Cardiol. 2018;72(6):662-80.

\section{Tables}

Due to technical limitations, Table 4 is only available as a download in the Supplemental Files section.

\section{Figures}

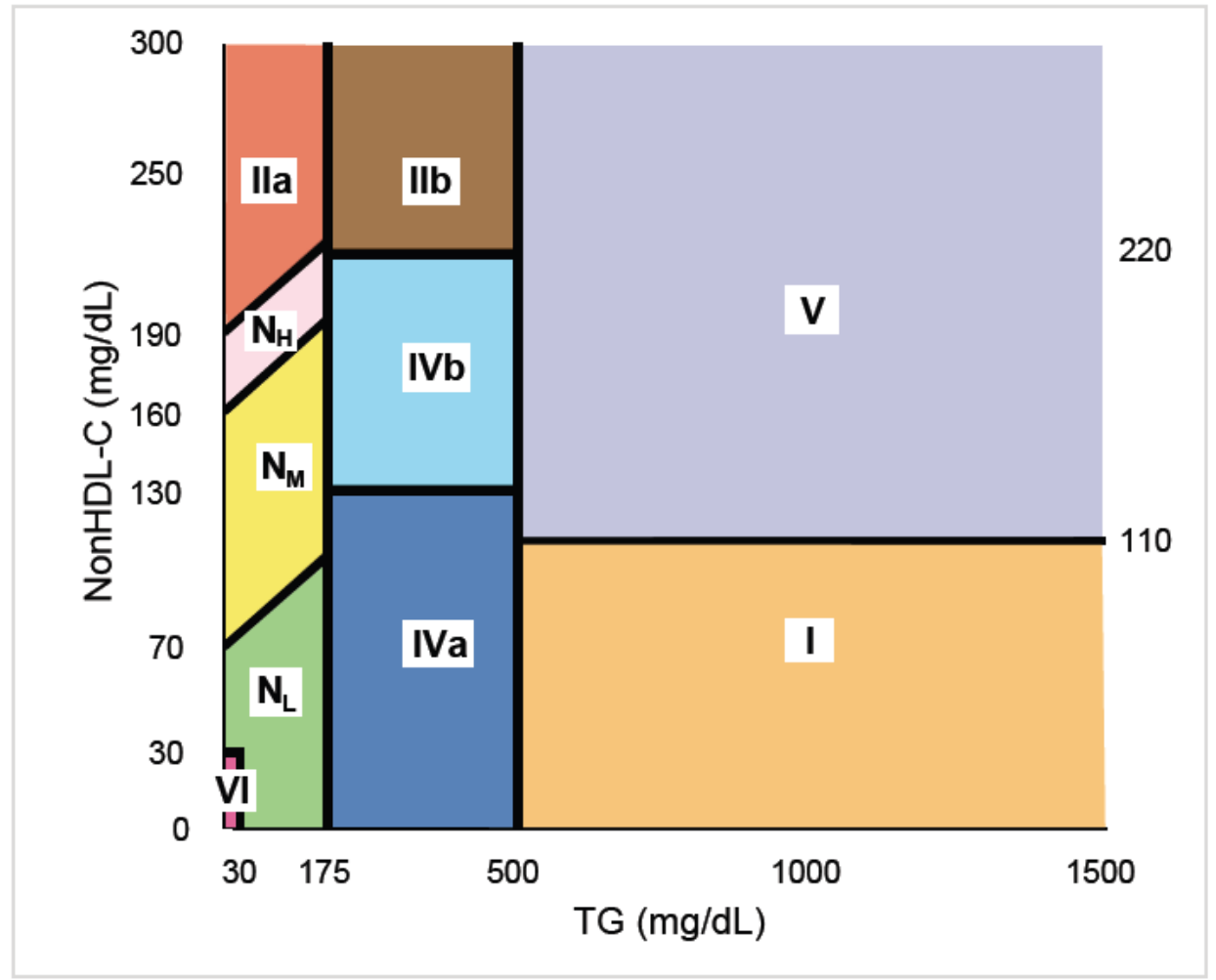

Figure 1

Diagram of new lipoprotein phenotyping classification system. Solid lines indicate various nonHDL-C and TG cut-points used to define various lipoprotein phenotypes (Type I-VI dyslipidemias, and the Normolipidemic subtypes ( High (H), Moderate (M) and Low (L)). Phenotypes are color coded as indicated. 

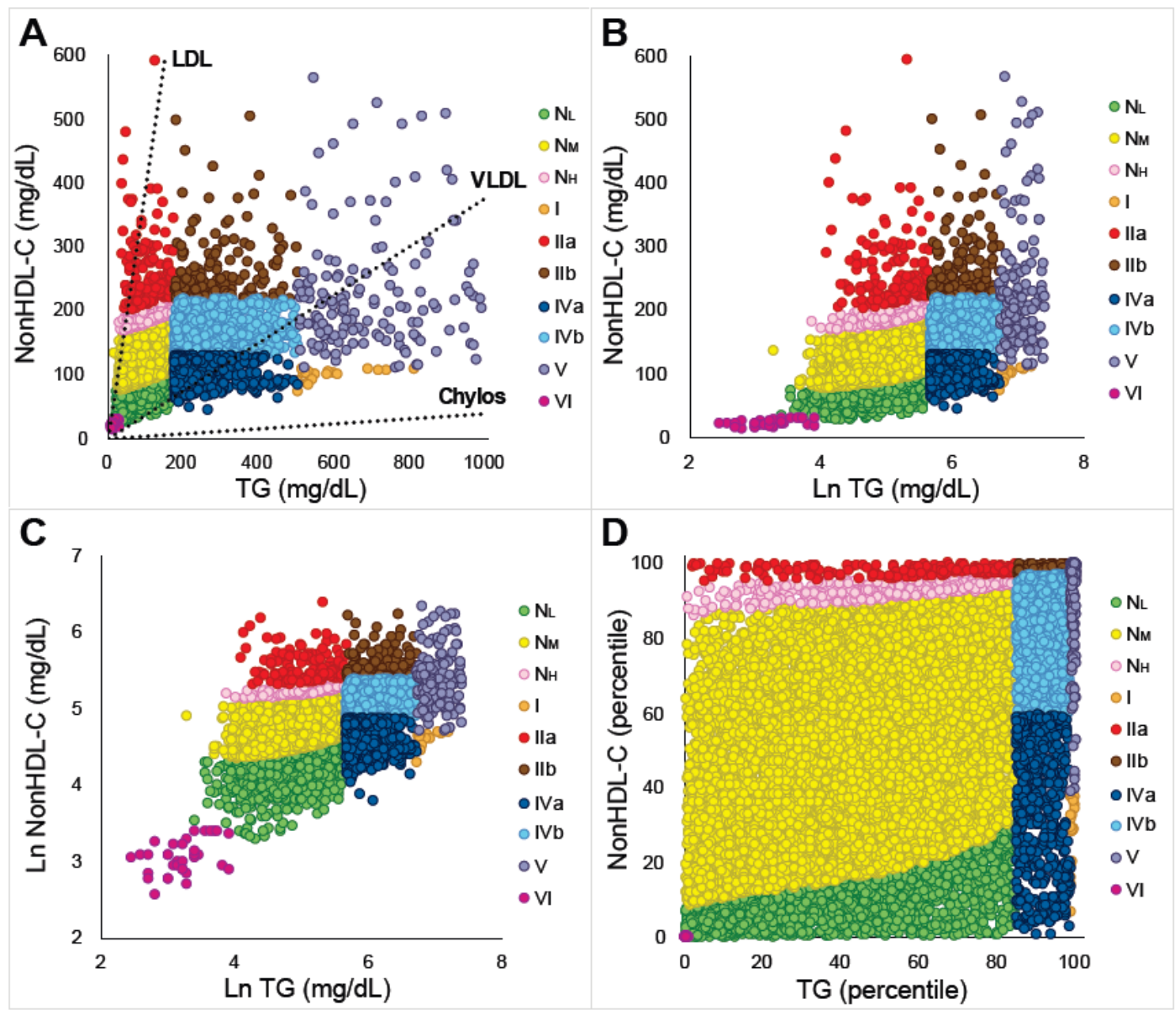

Figure 2

Lipoprotein phenotyping of subjects by new classification system. Samples $(\mathrm{N}=11,365)$ from patients seen at the $\mathrm{NIH}$, who were categorized into phenotypes based on NonHDL-C and TG rules (A) or as NonHDL-C and natural log TG (B) or as natural log NonHDL-C and natural log TG (C). NonHDL-C and TG were converted into percentiles and plotted as the percentile NonHDL-C versus percentile TG (D). Each point represents an individual sample. Phenotypes are color coded as indicated. Dotted lines in Panel A indicate cholesterol-to-TG ratio of indicated purified lipoproteins $(L D L-C=4, V L D L-C=0.4, C h y l o s=0.04)$. 

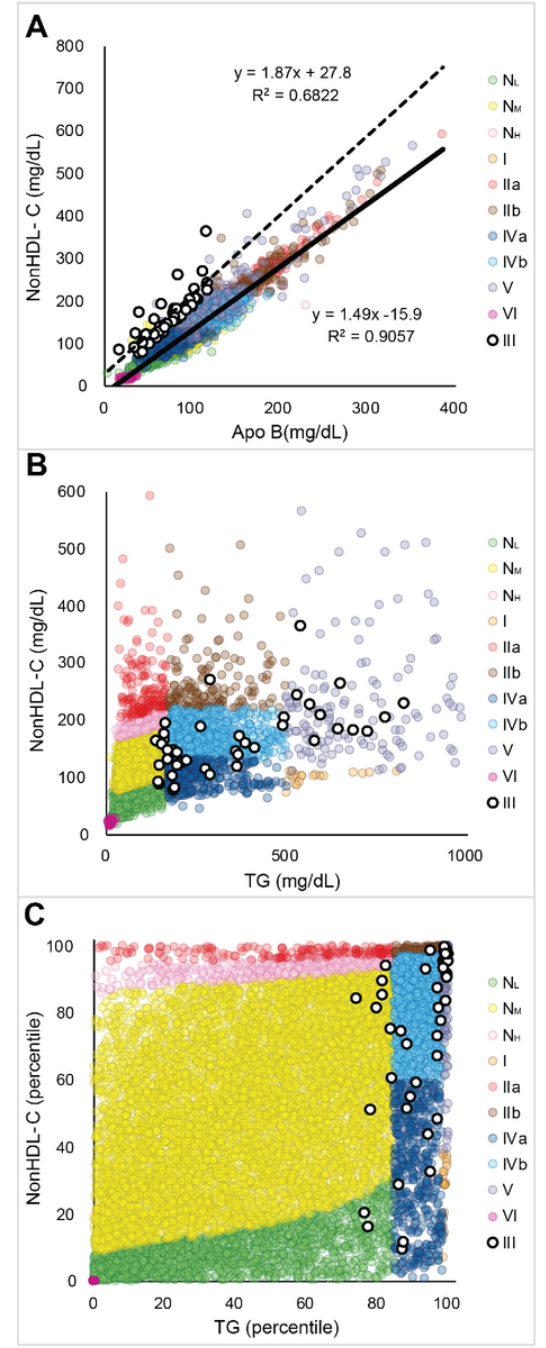

\section{Figure 3}

Classification of Type III phenotype by apoB-based decision rules. Regression analysis of NonHDL-C versus apoB for Type III patients (open white circles: dotted line) versus remaining phenotypes (color coded faint circles: solid line) for NIH samples $(\mathrm{N}=11,365)(\mathrm{A})$. Type III patients identified by the NonHDL$\mathrm{C} /$ apo B rule plus other Sniderman rules for Type III were (open white circles) versus other phenotypes (color coded faint circles) were plotted on graph of NonHDL-C versus TG (B). Type III patients identified by NonHDL-C/apo B rule plus other Sniderman rules for Type III (open white circles) were plotted onto percentile plot containing other phenotypes (color coded faint circles) (C). 


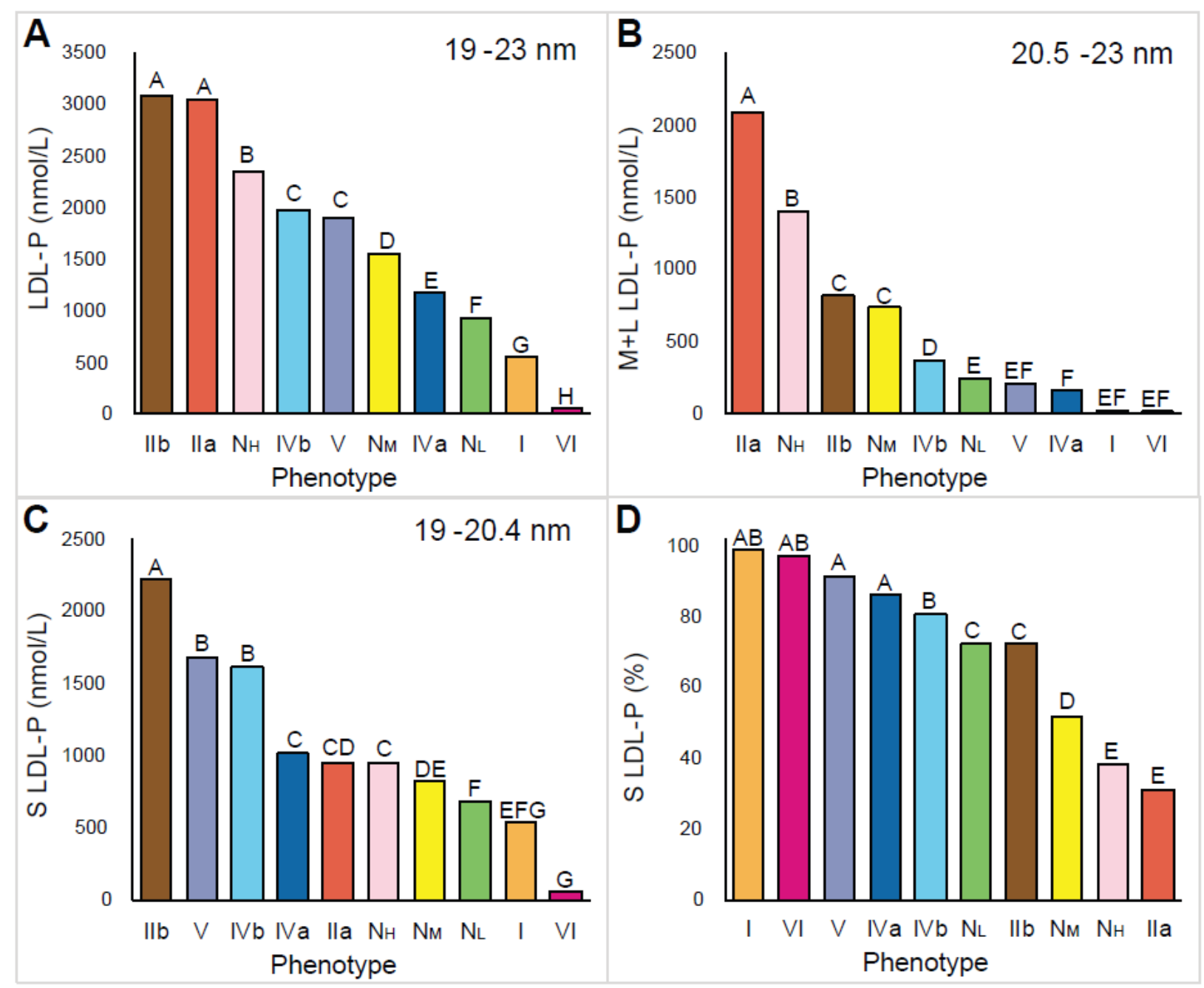

Figure 4

NMR lipoprotein particle parameters for LDL. Samples in NIH database (N=11,365) were analyzed by NMR for (A)Total LDL-P, (B) Large-medium LDL-P, (C) small LDL-P, and (D) \% small LDL-P. Capital letters indicate differences in group means as determined by ANOVA. 


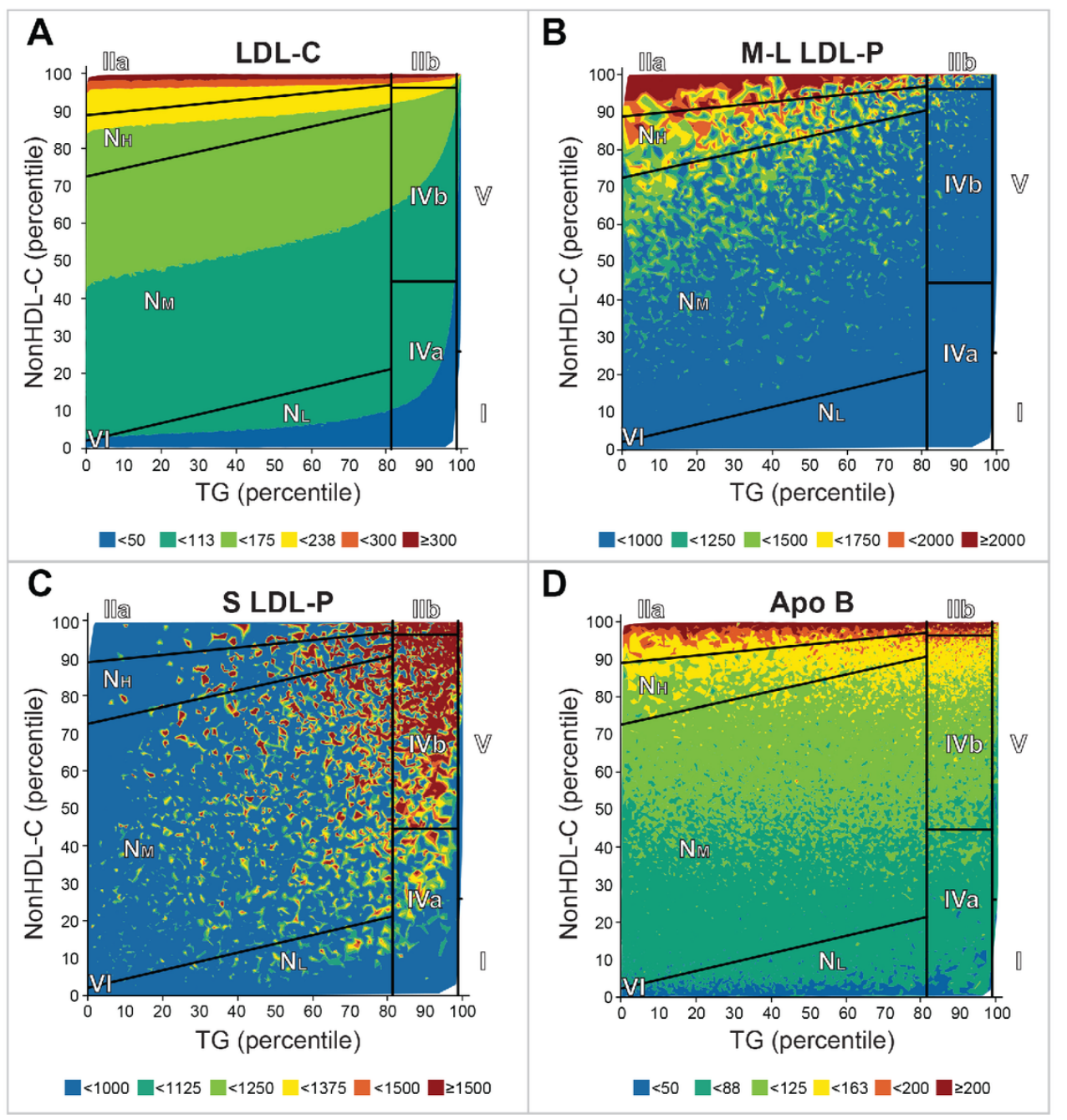

\section{Figure 5}

Contour plots for LDL related parameters. Samples in NIH database $(N=11,365)$ were analyzed for the following LDL related parameters and plotted as a contour plot: (A) LDL-C, (B) Large-medium LDL-P, (C) small LDL-P, and (D) apoB. 


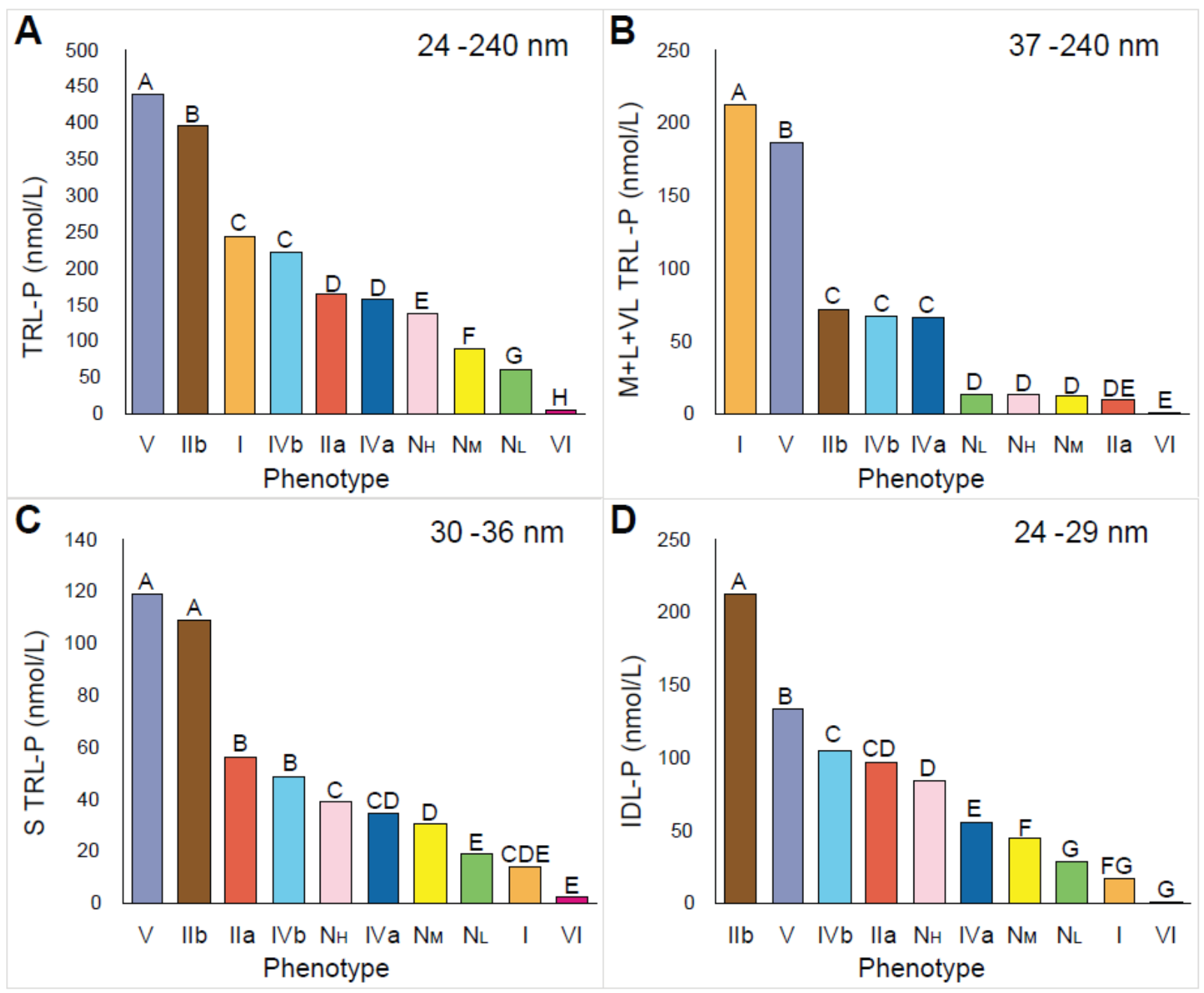

\section{Figure 6}

NMR lipoprotein particle parameters for TRL. Samples in NIH database $(N=11,365)$ were analyzed by NMR for $(A)$ total TRL-P, $(B)$ Very large-large-medium TRL, (C) small TRL, and (D) IDL. Capital letters indicate differences in group means as determined by ANOVA. 


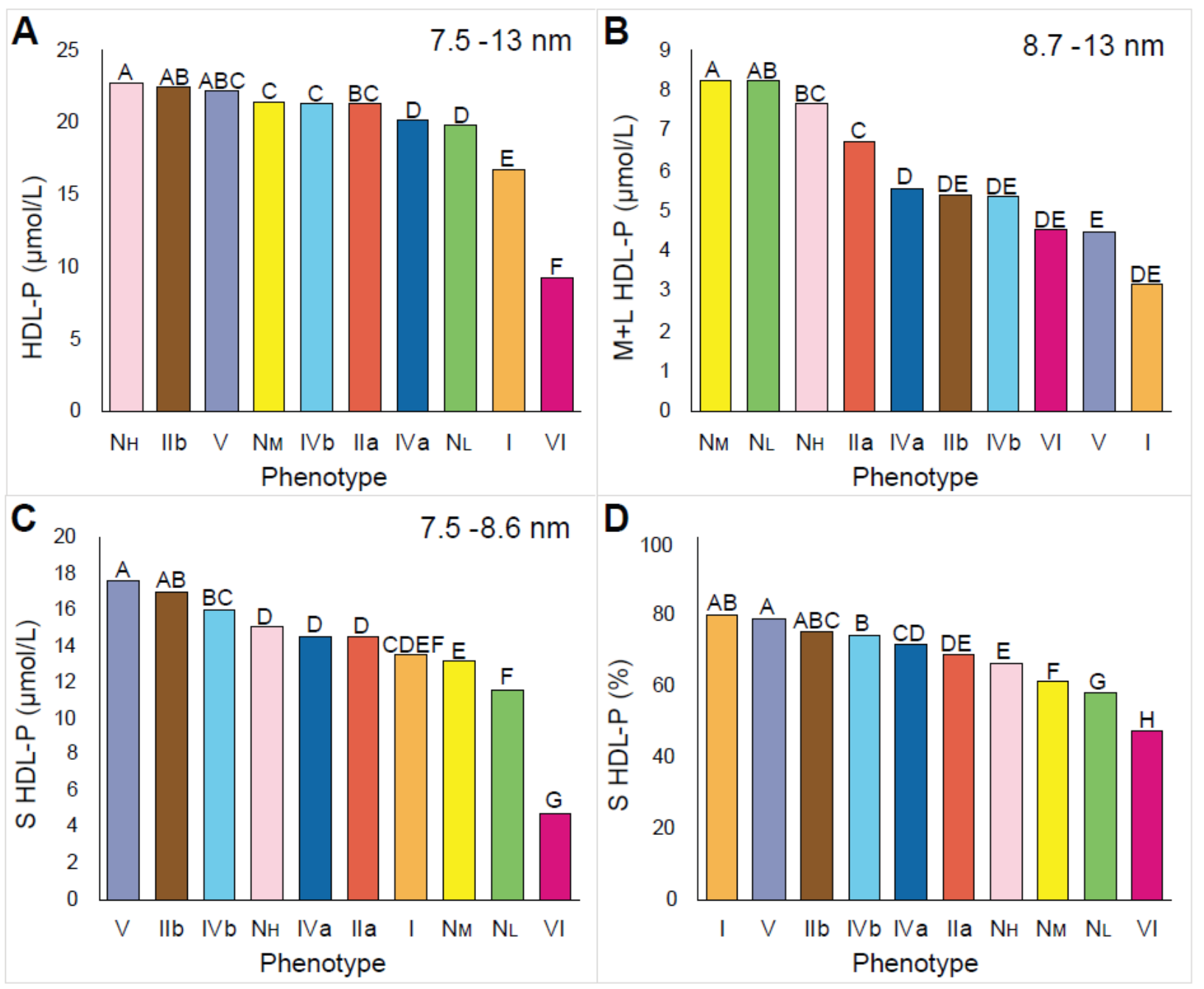

Figure 7

NMR lipoprotein particle parameters for HDL. Samples in NIH database $(N=11,365)$ were analyzed by NMR for (A) total HDL-P, (B) Large-medium HDL, (C) small HDL, and (D) \% small HDL-P. Capital letters indicate differences in group means as determined by ANOVA. 

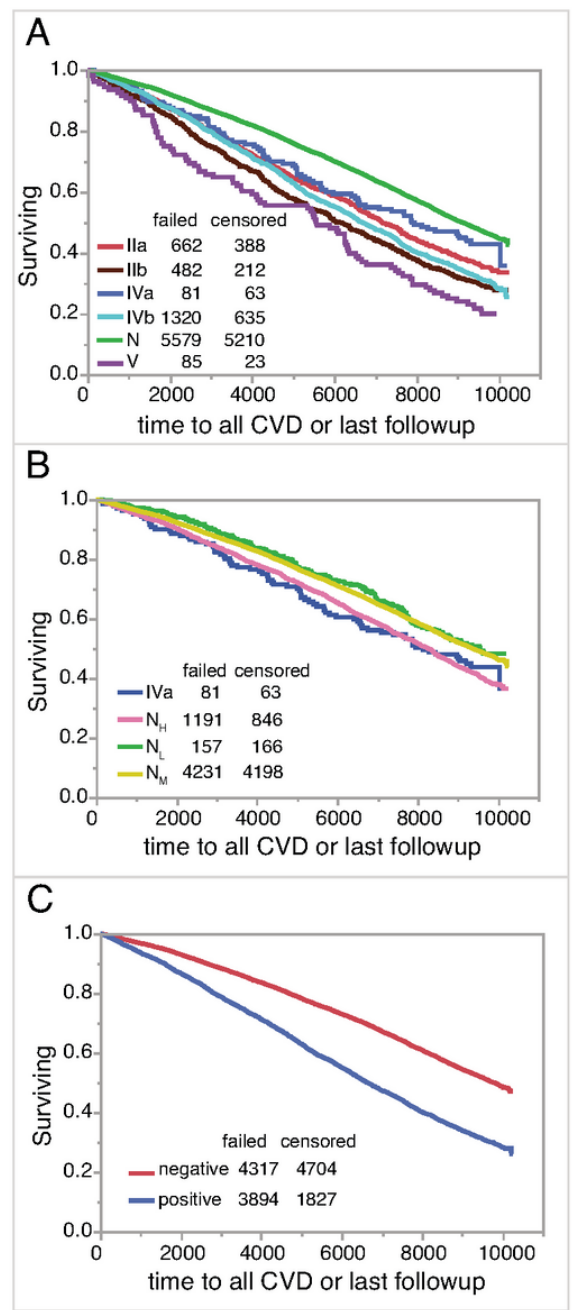

\section{Figure 8}

Survival curve analysis by lipoprotein phenotypes. Survival curves in ARIC (N=14742) for all ASCVD events were calculated for the indicated lipoprotein phenotypes (A and B) or for those with and without Metabolic Syndrome (C). For ARIC only baseline lipid results from the first study visit were used for analysis and ASCVD was defined as including the following: fatal and non-fatal myocardial infarction, revascularization, stroke and heart failure.

\section{Supplementary Files}

This is a list of supplementary files associated with this preprint. Click to download.

- Table4.docx

- SupplementalTable1.docx

- classificationsuppfig1.pdf

- classificationsuppfig2.pdf 